\title{
Designing Pd and Ni Catalysts for Cross-Coupling Reactions by Minimizing Off-Cycle Species
}

\author{
David Balcells*, Ainara Nova* \\ Hylleraas Centre for Quantum Molecular Sciences, Department of Chemistry, University of \\ Oslo, P.O. Box 1033, Blindern, Oslo 0315, Norway
}




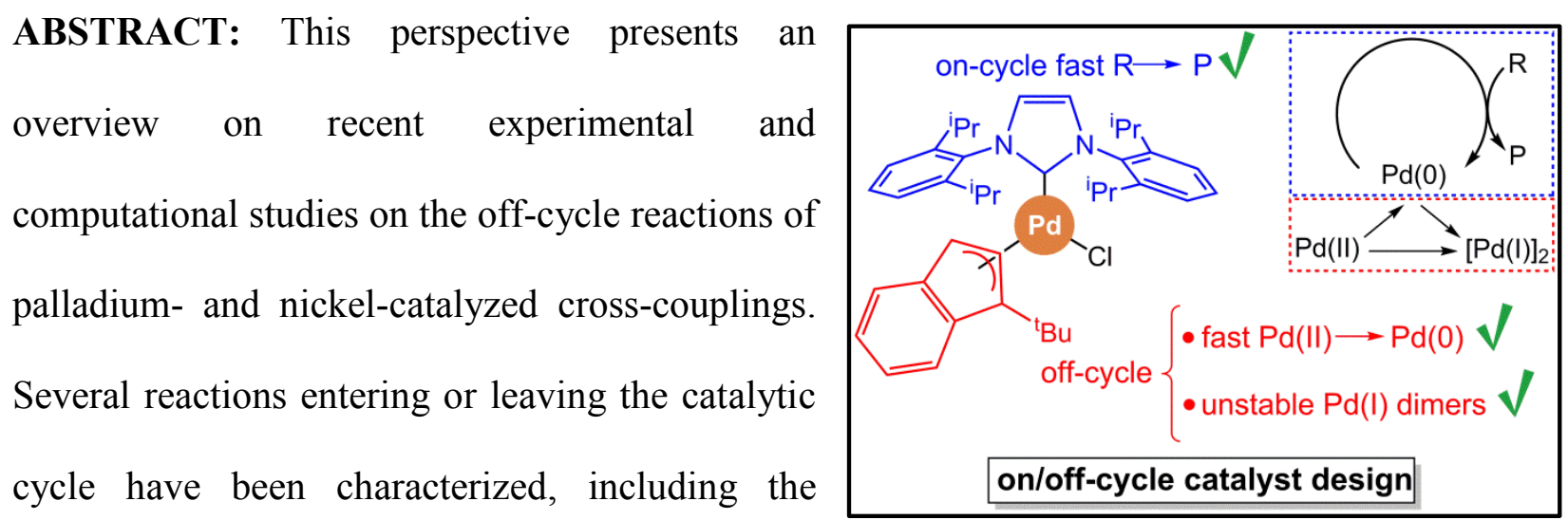

activation of $\mathrm{Pd}(\mathrm{II})$ precatalysts by $\mathrm{H}$-shift and the deactivation of $\mathrm{Ni}(\mathrm{II})$ precatalysts by comproportionation. A fundamental difference between the off-cycle chemistries of palladium and nickel is the larger diversity of species yielded by the latter, with a rich combination of different oxidation states, nuclearity and ligand coordination modes. The molecular-level understanding of off-cycle reactions has enabled new catalyst design strategies, including the stereoelectronic fine-tuning of the ligands aimed at maximizing the activation of the precatalyst meanwhile preventing its deactivation. Despite several challenges, which concern both experiments (e.g. isolation and characterization of transient species) and computations (e.g. comprehensive mapping of the potential energy surface), this approach has already been applied with success in the optimization of popular catalytic platforms (e.g. NHC-Pd-allyl precatalysts) and shows promise for the development of highly active and robust catalysts based on nickel.

KEYWORDS: off-cycle, catalysis, catalyst design, reaction mechanisms, cross-coupling, Suzuki-Miyaura, palladium, nickel, allyl, phosphine, DFT, mechanistic studies, precatalyst activation, deactivation, degradation, decomposition, dimer, dimerization. 


\section{INTRODUCTION}

Cross-coupling reactions are one of the most versatile and powerful tools in modern synthetic chemistry. $1,2,3,4,5,6,7,8,9,10,11,12,13,14,15,16$ With a wide range of applications, including the production of precursors for materials chemistry, pharmaceuticals and other fine chemicals, these reactions have become very important in both academia and in industry. Their practical application required the development of efficient catalysts, which was recognized with the Nobel Prize in Chemistry awarded to Heck, Negishi and Suzuki in $2010 .{ }^{17,18}$ Working with Miyaura, Suzuki reported the catalytic reaction now known by their names (Figure 1). ${ }^{19}$ In this reaction, a palladium catalyst promotes the $\mathrm{C}-\mathrm{C}$ coupling of an organic $\mathrm{R}-\mathrm{X}$ electrophile, e.g. an aryl halide, with an organoboron $\mathrm{R}^{\prime}-\mathrm{BY}_{2}$ nucleophile, e.g. a boronic acid, in the presence of a base. Beyond the catalytic advantages, i.e. milder conditions and wider scope from boosted kinetics, this reaction benefits through the use of organoboron compounds, which are cheap, relatively non-toxic and easy to separate.

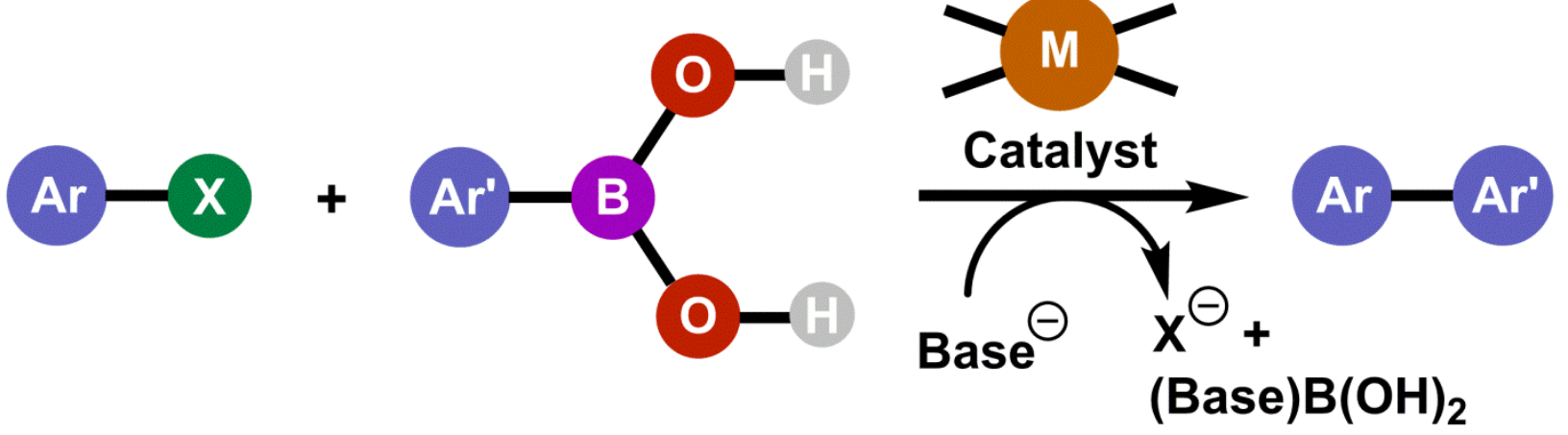

Figure 1. Generic depiction of the Suzuki-Miyaura cross-coupling reaction (e.g. $\mathrm{X}=$ halide, $\mathrm{M}=\mathrm{Pd}$ ). 
The reaction originally reported by Miyaura and Suzuki in 1979 stands out for the simplicity of the precatalyst used: $\mathrm{Pd}\left(\mathrm{PPh}_{3}\right)_{4}{ }^{20}$ In the last fifteen years, the quest for higher catalytic activity yielded a variety of fancier precatalysts, including those reported by Fu, ${ }^{21}$ Hartwig, ${ }^{22}$ Colacot, ${ }^{23}$ Nolan, ${ }^{24}$ Organ, ${ }^{25}$ Buchwald ${ }^{26,27}$ and Hazari ${ }^{28}$ (Figure 2). Many of these complexes are active for related cross-coupling reactions, including the Heck, ${ }^{29}$ Negishi $^{30}$ and Buchwald-Hartwig reactions, ${ }^{24}$ and have a common feature; i.e., they start as $\operatorname{Pd}(\mathrm{II})$ complexes with the same $\mathrm{Pd}: \mathrm{L}$ 1:1 ratio found in monoligated $\mathrm{Pd}(0)-\mathrm{L}(\mathrm{L}=$ phosphine or $\mathrm{NHC})$, which is the postulated active species in most catalytic reactions. ${ }^{31}$ Indeed, the development of these precatalysts has been largely based on mechanistic knowledge. The "textbook mechanism" of the Suzuki-Miyaura coupling (SMC) is shown in Figure 3 (on-cycle part). The catalytic cycle starts with the oxidative addition of the electrophilic substrate to $\operatorname{Pd}(0)-\mathrm{L}$. This yields a $\operatorname{Pd}(\mathrm{II})$ intermediate which undergoes transmetallation with the base-activated organoboron compound. The coupling product is formed by reductive elimination from the $(\mathrm{R})\left(\mathrm{R}^{\prime}\right) \mathrm{Pd}(\mathrm{II})-\mathrm{L}$ species. This mechanism has been thoroughly studied by both experimental and computational methods and subtle variants have been proposed, depending on the specific nature of the catalyst and reactants involved in each case. . $2,33,34,35,36,37,38,39,40,41,42,43,44$ Despite this mechanistic complexity, one catalyst design strategy has clearly emerged as a winner; i.e., to increase both the donor capacity and steric bulk of the ligand, which, in principle, should favor the on-cycle oxidative addition and reductive elimination steps, respectively. Further, these two factors also promote the productive off-cycle activation of the catalyst, which involves the formal reduction of the $\mathrm{Pd}(\mathrm{II})$ precatalyst to the $\operatorname{Pd}(0)$ active species. 


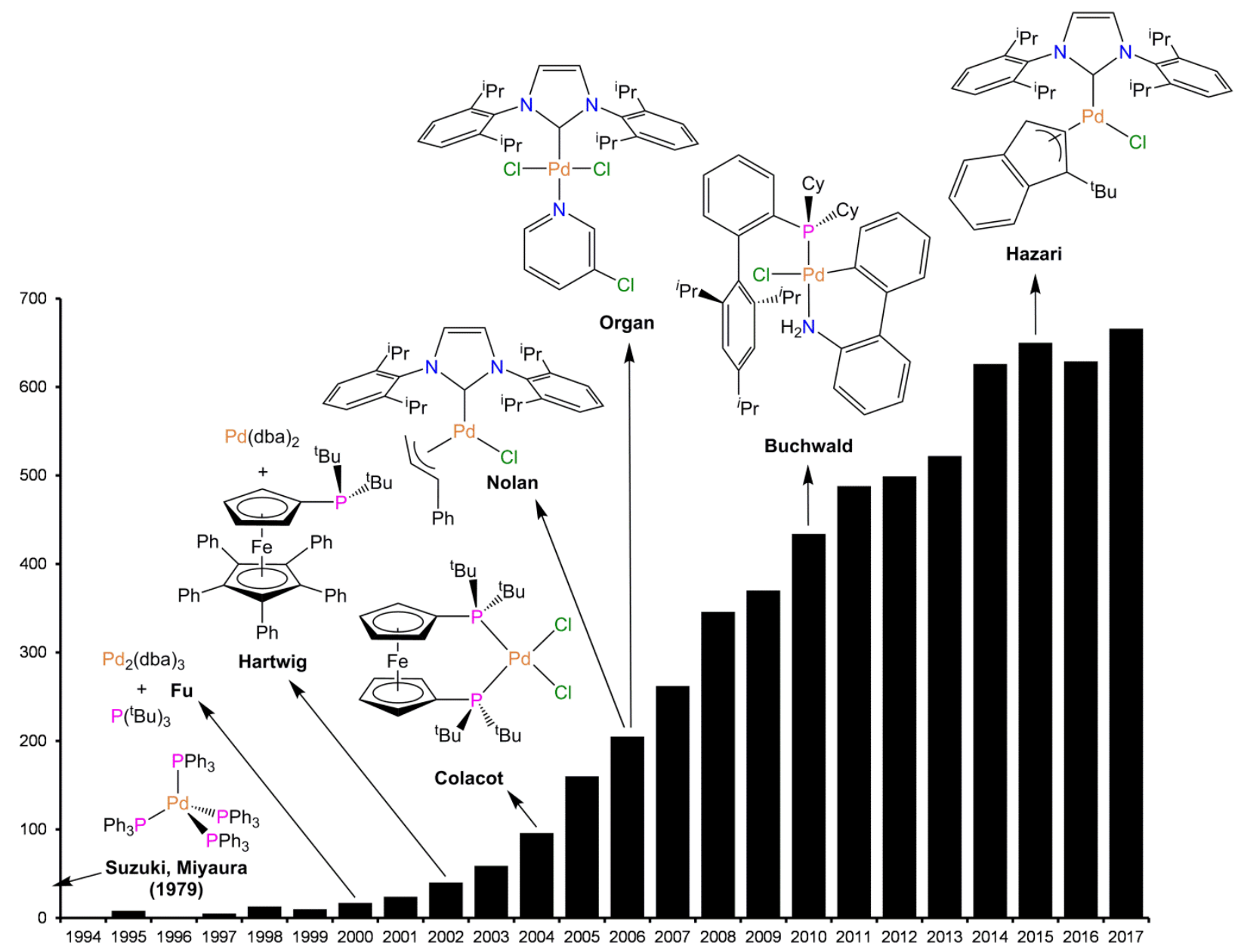

Figure 2. Number of publications per-year on the topic "Suzuki-Miyaura" according to the Web of Science ${ }^{\mathrm{TM}}$, with a selection of palladium catalysts. For the sake of clarity, the time range is restricted to 1994-2017.

The in-situ generation of the $\operatorname{Pd}(0)$ highly reactive species can also promote further off-cycle chemistry, including the formation of dimers, ${ }^{45,46,47,48}$ trimers, ${ }^{49,50}$ nanoparticles ${ }^{51}$ or Pd-black, ${ }^{52}$ which can be detrimental to catalysis. However, when properly formulated, polynuclear complexes can also be highly efficient cross-coupling precatalysts. ${ }^{53}$ The key role played by the off-cycle chemistry is well illustrated by the Nolan catalyst (Figure 2). In this specific case, the reaction yields are strongly dependent on the nature of the allyl substituents. ${ }^{54}$ Obviously, the catalytic cycle alone cannot account for this observation, since the on-cycle intermediates are 
supported by the NHC ligand rather than the allyl, which is eliminated upon activating the precatalyst. The off-cycle comproportionation of the $\operatorname{Pd}(\mathrm{II})$ precatalyst with the $\operatorname{Pd}(0)$ active species, yielding a $\mathrm{Pd}(\mathrm{I})-\mathrm{Pd}(\mathrm{I})$ dimer (Figure 3; $\mathrm{X}=$ bridging-allyl and $-\mathrm{Cl}$ ), should be considered. This dimer can be less reactive than the $\operatorname{Pd}(0)$ active species, thus having a detrimental effect when its formation is irreversible and kinetically competitive with the catalytic cycle. In line with this, the interplay between the on- and off-cycle reactions can have a dramatic effect on the reaction outcome. In the ideal scenario of a highly robust and active catalyst, the catalytic cycle is accelerated by combining fast activation with slow deactivation. ${ }^{55}$ In this way, the largest possible amount of metal species stays within the productive part of the mechanism for the longest time possible. This allows for high yields to be achieved with small amounts of metal and ligand, which can both be highly expensive.

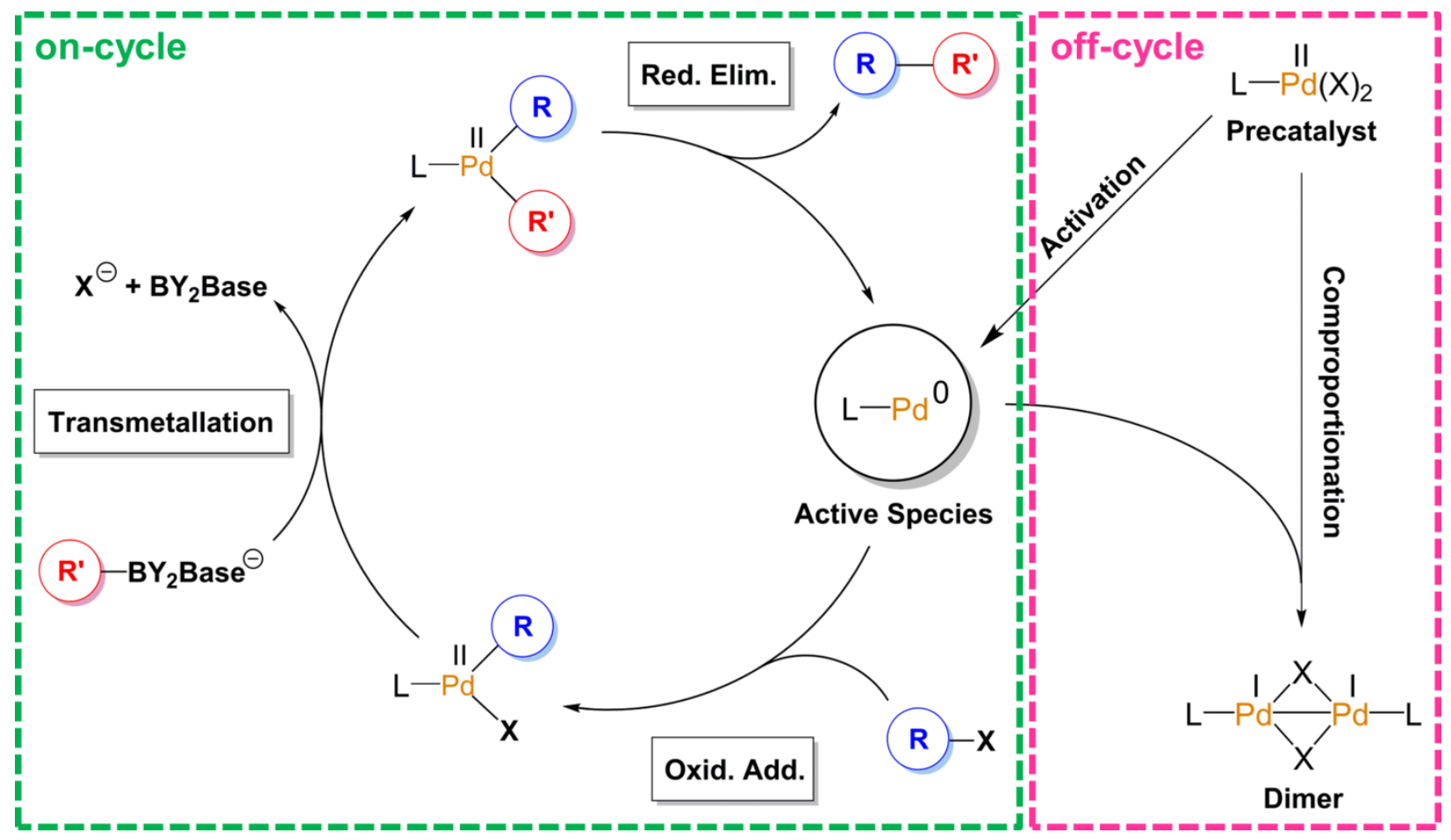

Figure 3. Mechanism of the Pd-catalyzed Suzuki-Miyaura coupling (SMC) showing both on- and off-cycle reactions. 
A rational approach to the development of new catalysts and the improvement of existing systems requires a deep knowledge of the overall catalytic cycle. In general, off-cycle chemistry is not as well understood as on-cycle reactions because most studies have followed the logic of focusing only on the productive part of the mechanism. Traditionally, these studies have tried to identify the on-cycle turnover limiting step and aimed catalyst design at its acceleration. Sophisticated models based on quantum mechanics calculations have been used for this purpose, including the energetic span model ${ }^{56,57}$ and reaction networks. ${ }^{58,59}$ However, these models may not work or yield results that are not fully satisfactory. This problem can originate from complex rate laws depending on the kinetic parameters of several reactions, including those that are off-cycle. ${ }^{60}$ One interesting feature of the latter is that, like the on-cycle, they are often not specific for a single catalytic reaction but rather general to several reactions. E.g., precatalyst activation by formal $\mathrm{Pd}(\mathrm{II}) \rightarrow \mathrm{Pd}(0)$ reduction in the $\mathrm{SMC}$ is also relevant in the Heck and Negishi couplings, since they also required the formation of a $\operatorname{Pd}(0)$ species which will undergo oxidative addition. Further, the intermediate oxidation state I is also relevant in nickel-catalyzed cross-couplings because monomeric $\mathrm{Ni}(\mathrm{I})$ species can have a detrimental effect on catalysis. ${ }^{61}$ The deactivation mechanisms of catalysts based on $4 d$ and $5 d$ metals can thus provide useful insight for the development of new systems based on the cheaper and less toxic $3 d$ metals. ${ }^{62,63,64,65,66,67}$

Despite the biased attention of mechanistic studies towards on-cycle steps, a fair amount of data is already available for off-cycle deactivation reactions. The topic was recently reviewed by Crabtree, who classified these reactions on the basis of their cause, including ligand-centered reactions and inhibition by different agents, and discussed how they can be excluded or mitigated. ${ }^{68}$ However, experimental evidence on these processes is still scarce because they 
involve highly reactive intermediates that are difficult or impossible to characterize. In this scenario, computational chemistry is a powerful tool to increase understanding of off-cycle chemistry, due to its ability to characterize both transition states and intermediates. Further, the excellent accuracy/cost ratio already achieved by DFT methods now allows combining computational and experimental studies towards a common goal, in a parallel and symbiotic manner. ${ }^{69,70,71,72,73,74,75,76,77}$ Most of these studies have been enabled by state-of-the-art DFT methods, ${ }^{78}$ including meta-GGA functionals with Laplacian-dependent terms (e.g. M06 functional $)^{79,80,81}$ and dispersion corrections (e.g., Grimme's model). ${ }^{82,83}$ Double- and triple- $\zeta$ quality basis sets are used with polarization and diffuse functions, plus effective core potentials, for an accurate description of covalent bonds, charge delocalization and relativistic effects on transition metal complexes. The calculations are carried out on realistic models including the full system (i.e. real ligand and substrate, without structural simplifications) with mixed solvation. The latter combines implicit (continuum solvent; e.g. SMD model) and explicit (discrete coordinating molecules) solvent representations, which are used both in geometry optimization and energy refinement. ${ }^{84,85,86,87,88}$

This Perspective focuses on the development of precatalysts for cross-coupling reactions based on the study and optimization of off-cycle reactions. Recent examples have been selected to illustrate how both experiments and computations were used (and often combined) to provide a rational approach to catalyst design in this novel context. The activation mechanisms of palladium precatalysts and their relation to dimerization are presented. The more recent application of this approach to the optimization of catalysts based on nickel is also discussed. 


\section{Pd(II) $\rightarrow$ Pd(0) ACTIVATION OF PRECATALYST MONOMERS}

Since most of the catalytic systems shown in Figure 2 involve the use of $\operatorname{Pd}(\mathrm{II})$ complexes, cross-coupling requires their activation by formal reduction to $\operatorname{Pd}(0)$ (Figure 3). For optimal catalysis, this reaction should be both exoergic and fast. With Pd-allyl precatalysts, different activation mechanisms have been proposed on the basis of the olefin byproducts observed, which depend on the nature of the ancillary ligands and the reaction conditions (e.g. base and solvent used). ${ }^{89,90,91}$

The activation of $\mathrm{Pd}(\mathrm{II}) \operatorname{Pd}(\mathrm{IPr})(\mathrm{Cl})($ allyl) and $\mathrm{Pd}(\mathrm{IPr})(\mathrm{Cl})($ indenyl) precatalysts to $\mathrm{Pd}(0)$ in the presence of alcoholic solvents was studied in detail by Melvin and co-workers, combining theory with experiments. ${ }^{92}$ As shown in Figure 4 for the allyl ligand, the activation mechanism starts with the substitution of the chloride ligand by methoxide, which forms upon deprotonation of the solvent by the ${ }^{t} \mathrm{BuOK}$ base. For all ligands considered in this study (allyl, cinnamyl, indenyl and 1- ${ }^{t} \mathrm{Bu}$-indenyl), the substitution reaction follows a dissociative rather than associative mechanism. Once the methoxide is bound to the metal center, the formation of the olefin and carbonyl products detected in the experiments requires transferring one hydride to the allyl. A possible reaction pathway involves $\beta-\mathrm{H}$ elimination followed by reductive elimination (Figure 4a). ${ }^{93,94}$ Though the latter step is facile, being both exoergic and low-barrier $\left(\Delta \mathrm{G}_{\mathrm{RE}}=-17.6\right.$ and

$\left.\Delta \mathrm{G}_{\mathrm{RE}}^{\dagger}=13.7 \mathrm{kcal} \mathrm{mol}^{-1}\right), \beta-\mathrm{H}$ elimination is encumbered by the prohibitive energy barrier associated with the dissociation of formaldehyde $\left(\Delta \mathrm{G}^{\dagger} \mathrm{HE}=32.5 \mathrm{kcal} \mathrm{mol}^{-1}\right)$. This reaction pathway was also excluded for the cinnamyl, indenyl and $1-^{t} \mathrm{Bu}$-indenyl ligands, which yielded similar energy profiles. An alternative mechanism is a direct ligand-to-ligand $\mathrm{H}$-shift from the methoxide to the allyl (Figure 4b). This pathway involves a transition state with concerted C- 
$1_{\text {ally }} \cdots \mathrm{H}^{\cdots} \mathrm{C}_{\text {methoxyde }}$ bond cleavage/formation. The associated energy barrier, $\Delta \mathrm{G}^{+} \mathrm{HS}=24.5 \mathrm{kcal}$ $\mathrm{mol}^{-1}$, is clearly lower than that of $\beta-\mathrm{H}$ elimination and more consistent with the mild conditions used in the experiments. Interestingly, nearly half of the $\mathrm{H}$-shift barrier is required to reach the pre-reaction complex, in which the allyl ligand had slipped from the $\eta^{3}$ - to $\kappa^{1}$-coordination mode

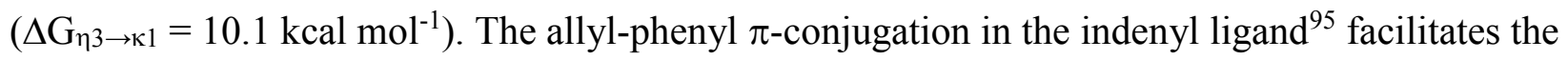
$\eta^{3} \rightarrow \kappa^{1}$ rearrangement $\left(\Delta \mathrm{G}_{\eta 3 \rightarrow \kappa 1}=5.5 \mathrm{kcal} \mathrm{mol}^{-1}\right)$, yielding a lower H-shift energy barrier $\left(\Delta \mathrm{G}^{\ddagger} \mathrm{HS}=21.7 \mathrm{kcal} \mathrm{mol}^{-1}\right)$. In agreement with this, experimental kinetics based on the use of dvds (divinyl-1,1,3,3-tetramethyldisiloxane) as a $\operatorname{Pd}(0)$ trap, showed that the activation of the indenyl precatalysts was faster than that of the allyl. 
<smiles>CC=[Ge](Cl)C=N</smiles>

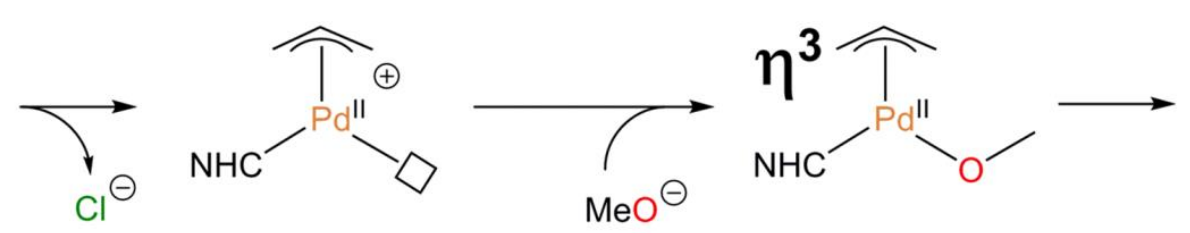

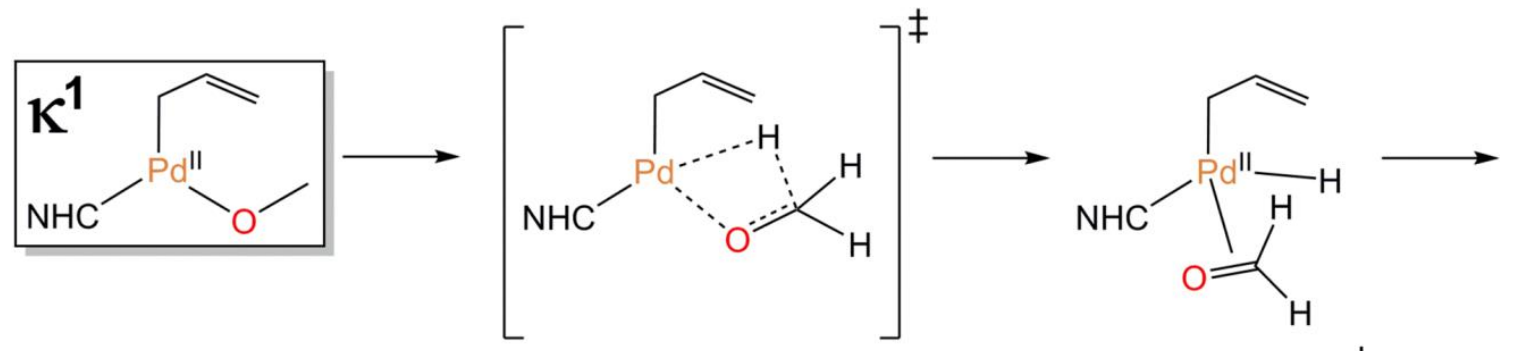

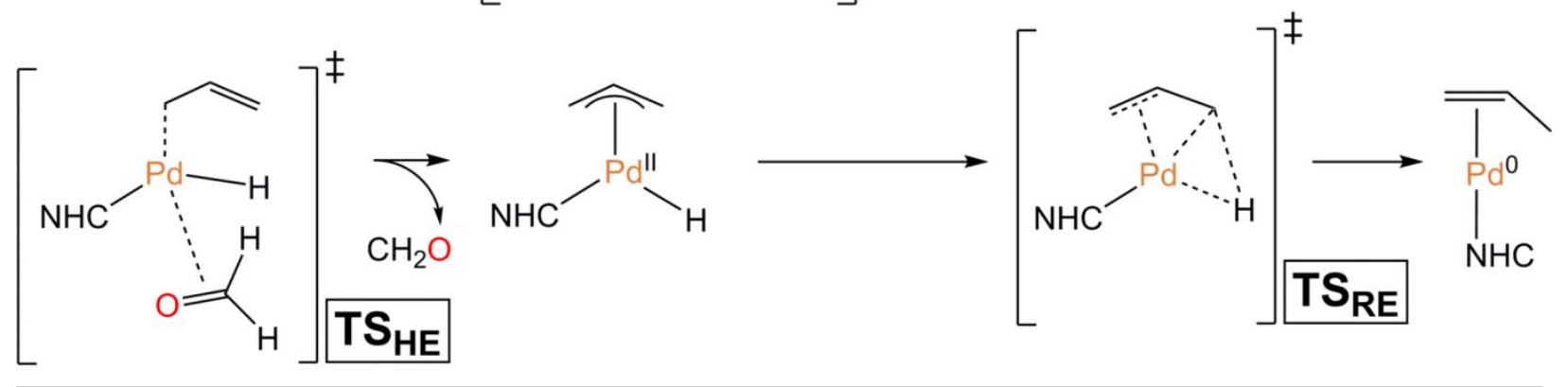

b)

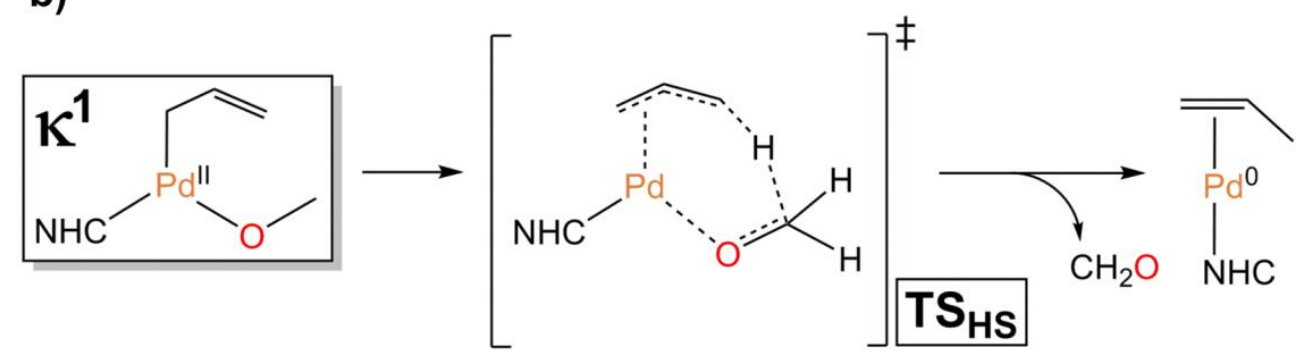

c)

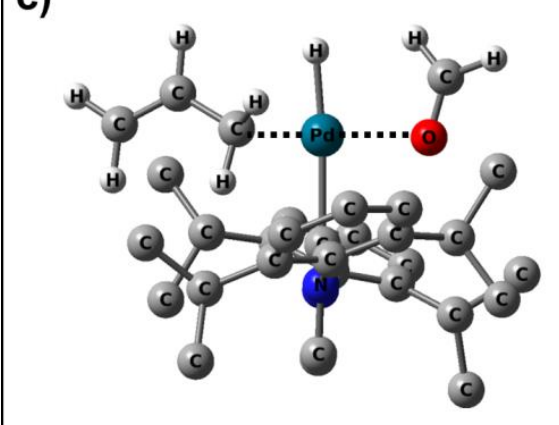

$\mathrm{TS}_{\mathrm{HE}}$

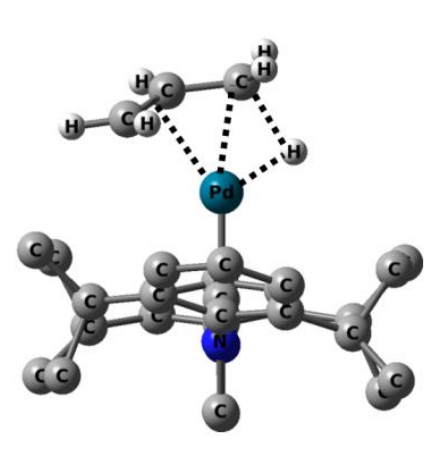

$\mathrm{TS}_{\mathrm{RE}}$

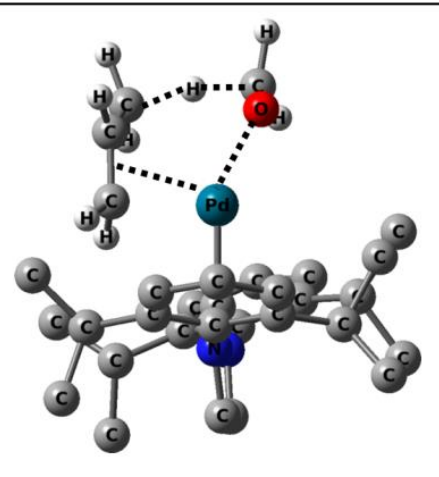

$\mathrm{TS}_{\mathrm{HS}}$

Figure 4. Activation of $\mathrm{Pd}(\mathrm{IPr})(\mathrm{Cl})($ allyl) by a) $\beta-\mathrm{H}$ elimination $(\mathrm{HE})+$ reductive elimination $(\mathrm{RE})$ and $b$ ) hydrogen shift (HS); c) DFT-optimized key transition states. The H atoms of the IPr ligand were removed for clarity. 
In addition to the $\mathrm{H}$-shift mechanism, the addition of the base to the allyl group followed by reductive elimination of the ether has been proposed. This reaction may occur following two different pathways: 1) intramolecular addition of the alkoxide, which has been previously coordinated to Pd by ligand exchange, or 2) direct intermolecular addition of the alkoxide to the allyl ligand. ${ }^{96}$ In a computational study, Meconi and co-workers found a low-energy pathway only for the former mechanism, involving the $\mathrm{IPr}$ carbene ligand and ${ }^{t} \mathrm{BuO}^{-}$as base. ${ }^{97}$ The energy barriers for different allyl ligands (Figure 5) followed the trend allyl $>$ prenyl $>$ crotyl $>$ cinnamyl. However, when using the bulky phosphine Q-Phos instead of IPr, the crotyl system outperforms both the allyl and cinnamyl in the amination of aryl bromides. ${ }^{98}$ Based on the crystal structure of the different substituted-allyl precatalysts, this preference was ascribed to the higher accessibility of the crotyl ligand in the direct intermolecular addition of the alkoxide.

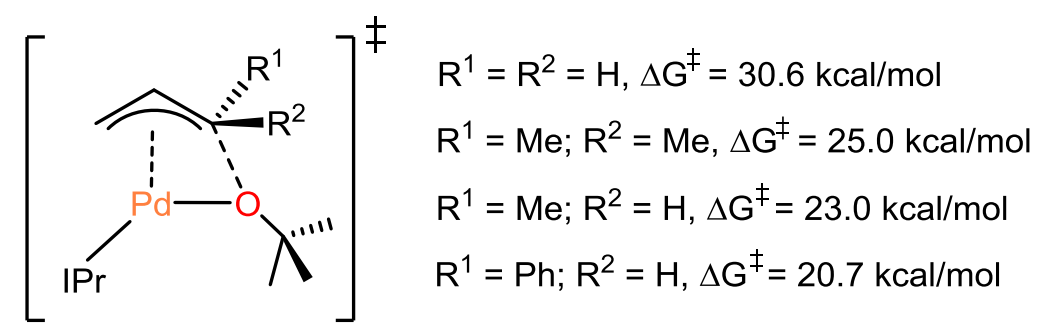

Figure 5. Free energy barriers in isopropanol for the addition of tert-butoxide to different allyl ligands in the activation of $\left[\operatorname{Pd}(\operatorname{IPr})\left(\mathrm{R}^{1}, \mathrm{R}^{2}\right.\right.$-allyl $\left.) \mathrm{Cl}\right]$ precatalysts. 


\section{$\operatorname{Pd}(I) \rightarrow \operatorname{Pd}(0)$ ACTIVATION OF PRECATALYST DIMERS}

The formation of $\operatorname{Pd}(0)$ species from air-stable $\operatorname{Pd}(\mathrm{I})$ dimers under basic conditions allows for using the latter as cross-coupling precatalysts. ${ }^{99,100}$ This strategy has been explored by the group of Schoenebeck using the complexes $\left[\left(\mathrm{P}^{t} \mathrm{Bu} 3\right) \mathrm{Pd}(\mu-\mathrm{Br})\right]_{2}$ and $\left[\left(\mathrm{P}^{t} \mathrm{Bu} 3\right) \operatorname{Pd}(\mu-\mathrm{I})\right]_{2}$ (Figure 6), which also work as on-cycle catalysts for the coupling of $\mathrm{C}-\mathrm{S}$ and $\mathrm{C}-\mathrm{Se}$ bonds. ${ }^{101,102}$ In a combined experimental-computational study using $\left[\left(\mathrm{P}^{t} \mathrm{Bu} u_{3}\right) \mathrm{Pd}(\mu-\mathrm{Br})\right]_{2}$ as a precatalyst, different product selectivities were observed depending on the solvent polarity: while the C-OTf bond of the organic electrophile was preferentially activated in acetonitrile, the $\mathrm{C}-\mathrm{Cl}$ bond was activated in THF. ${ }^{103}$ This observation was rationalized by calculations considering different charges for the mono-ligated $\operatorname{Pd}(0)$ active species (e.g. anionic in acetonitrile, neutral in THF) resulting from the dissociative activation of the dimer by a base (e.g. $\mathrm{F}^{-}$or $\left.\operatorname{Ar}(\mathrm{OH}) \mathrm{BO}^{-}\right) .{ }^{104}$ The differences in the

oxidative addition barrier for $\mathrm{C}-\mathrm{OTf}$ and $\mathrm{C}-\mathrm{Cl}$ to the anionic $\left[\left(\mathrm{P}^{t} \mathrm{Bu}_{3}\right) \mathrm{Pd}(\mathrm{F})\right]^{-}$and $\left[\left(\mathrm{P}^{t} \mathrm{Bu}_{3}\right) \mathrm{Pd}(\mathrm{OB}(\mathrm{OH}) \mathrm{Ar}]^{-}\right.$species are 2.3 and $3.9 \mathrm{kcal} \mathrm{mol}^{-1}$, both in favor of the former bond. In contrast, with the neutral $\left[\left(\mathrm{P}^{t} \mathrm{Bu} 3\right) \mathrm{Pd}\right]$ species, the energy barrier for the $\mathrm{C}-\mathrm{Cl}$ oxidative addition is lower than that of the $\mathrm{C}-\mathrm{OTf}$ by $5.8 \mathrm{kcal} \mathrm{mol}^{-1}$. The assumption of having $\mathrm{Pd}(\mathrm{I})$ active species did not explain the selectivity observed experimentally and yielded prohibitive oxidative addition barriers over $45 \mathrm{kcal} \mathrm{mol}^{-1}$. These findings supported the hypothesis that the $\left[\left(\mathrm{P}^{t} \mathrm{Bu} 3\right) \operatorname{Pd}(\mu-\mathrm{Br})\right]_{2}$ dimer precatalyst yields monomer active species in the $\operatorname{Pd}(0)$ oxidation state rather than in the $\operatorname{Pd}(\mathrm{I})$. However, thermodynamic calculations on different dissociation pathways starting from the dimer showed that $\mathrm{Pd}(\mathrm{I})$ monomer products are preferred over $\mathrm{Pd}(0)$ and $\mathrm{Pd}(\mathrm{II})$. 
off-cycle activation
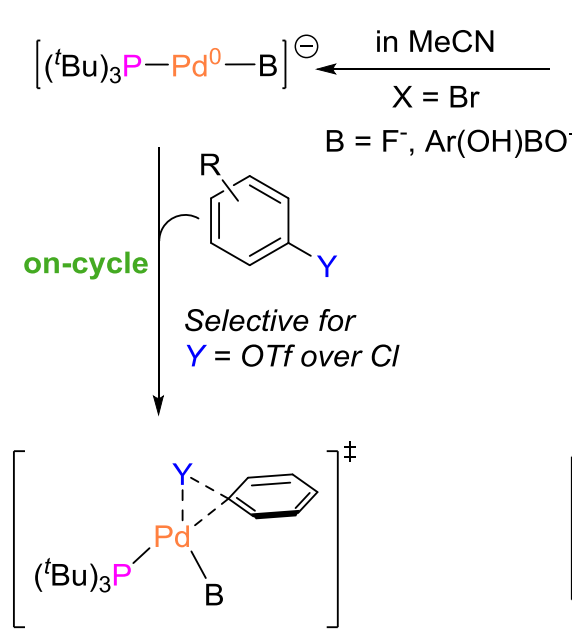

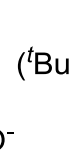

$\left({ }^{t} \mathrm{Bu}\right)_{3} \mathrm{P}-\left.\mathrm{Pd}\right|_{\mathrm{X}}{ }^{\mathrm{X}}{ }^{\mathrm{P} \mathrm{d}^{l}-\mathrm{P}\left({ }^{t} \mathrm{Bu}\right)_{3}}$
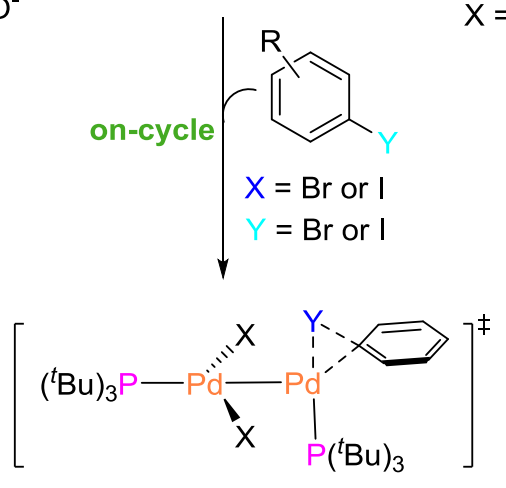

off-cycle activation

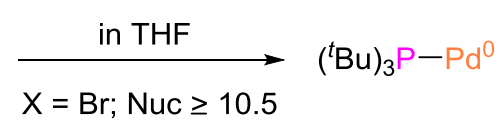

$X=I ;$ Nuc $\geq 16.1$
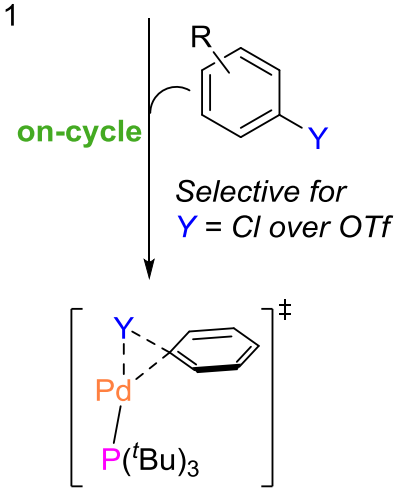

Figure 6. Precatalyst and electrophile activation with $\left[\left(\mathrm{P}^{t} \mathrm{Bu} 3\right) \operatorname{Pd}(\mu-\mathrm{X})\right]_{2}$ dimers. The parameter $N u c$ refers to the Mayr nucleophilicity scale.

In order to gain further insight into the activation mechanism of $\left[\left(\mathrm{P}^{t} \mathrm{Bu} 3\right) \mathrm{Pd}(\mu-\mathrm{Br})\right]_{2}$ to generate $\operatorname{Pd}(0)$ active species, the reactivity of this dimer was studied by Aufiero and co-workers using different bases. ${ }^{105}$ In the presence of $\mathrm{KF}$ and aryl-boronic acids in THF, $\left[\left(\mathrm{P}^{t} \mathrm{Bu} 3\right) \mathrm{Pd}(\mu-\mathrm{Br})\right]_{2}$ is converted to $\left[\mathrm{Pd}\left(\mathrm{PtBu}_{3}\right)_{2}\right]$ and Pd-black. Under the same conditions, the addition of arylchlorides yielded SMC products with high conversions. These observations were consistent with the activation of the dimer to $\operatorname{Pd}(0)$ in the presence of a base. In line with this, the rather inactive and air-stable $\left[\left(\mathrm{P}^{t} \mathrm{Bu} u_{3}\right) \mathrm{Pd}(\mu-\mathrm{I})\right]_{2}$ dimer was also activated using stronger bases such as ${ }^{t} \mathrm{BuOK}$. The combination of this base with the $\left[\left(\mathrm{P}^{t} \mathrm{Bu} 3\right) \mathrm{Pd}(\mu-\mathrm{Br})\right]_{2}$ dimer yielded larger amounts of Pdblack during catalysis. This indicated that a careful selection of the base is required to modulate the rate at which the $\operatorname{Pd}(0)$ active species is generated to prevent its off-cycle decomposition, yet maximizing the on-cycle activation of the electrophile. Experiments using a series of different nucleophiles across the Mayr scale (Nuc in Figure 6) ${ }^{106}$ established the minimum nucleophilicity required for the activation of the $\mu-\mathrm{Br}-$ and $\mu-\mathrm{I}-\mathrm{Pd}(\mathrm{I})$ dimers $(N u c=10.5$ and 16.1 , respectively). 
In addition to alkoxy bases, nucleophilic organometallic complexes such as Grignard reagents can be used to activate these precatalysts.

Following these studies, Kalvet and co-workers showed that $\left[\left(\mathrm{P}^{t} \mathrm{Bu}\right) \operatorname{Pd}(\mu-\mathrm{I})\right]_{2}$ can be used as a precatalyst for $\mathrm{C}_{\mathrm{sp}^{2}}-\mathrm{C}_{\mathrm{sp}^{2}}$ and $\mathrm{C}_{\mathrm{sp}^{2}-\mathrm{C}_{\mathrm{sp}}{ }^{3}}$ Kumada and Negishi coupling reactions under mild conditions. ${ }^{107,108}$ These reactions are highly chemoselective for the activation of $\mathrm{C}-\mathrm{Br}$ bonds, in the presence of the $\mathrm{C}-\mathrm{Cl}$ and $\mathrm{C}-\mathrm{OTf}$ bonds. Energy barrier calculations on the oxidative addition of these $\mathrm{C}-\mathrm{X}$ bonds to mononuclear $\mathrm{Pd}(0)$ and dinuclear $\mathrm{Pd}(\mathrm{I})$ species did not provide insight about the nature of the active catalyst, since both had a preference for the cleavage of the $\mathrm{C}-\mathrm{Br}$ bond. The high and unusual selectivity observed in these reactions was rationalized in terms of the absence of interfering active species, which is consistent with the fast recovery of $\left[\left(\mathrm{P}^{t} \mathrm{Bu}\right)_{3}\right) \operatorname{Pd}(\mu-\mathrm{I})_{2}$ upon addition of iodide salts and $\mathrm{PhMgCl}$ to $\mathrm{Pd}(0)\left(\mathrm{P}^{t} \mathrm{Bu}_{3}\right)_{2}$. However, other studies by the Schoenebeck group showed that these observations may also indicate that the dimer, which exchanges $\mathrm{Br}^{-}$by $\mathrm{I}^{-}$via reversible oxidative addition, is the on-cycle catalyst, without requiring off-cycle activation. ${ }^{109,110}$ This would involve either the formation of dinuclear aryl intermediates, related to the species observed with nickel by Matsubara and co-workers, ${ }^{11}$ or the dissociation of the dimer into $\mathrm{Pd}(\mathrm{II})$ monomers after oxidative addition. 


\section{CATALYST DEACTIVATION BY FORMATION OF Pd(I) DIMERS}

In the same way that $\operatorname{Pd}(\mathrm{I})$ dimeric precatalysts can be activated by disproportionation to $\operatorname{Pd}(0)$ and $\mathrm{Pd}(\mathrm{II})$ species, ${ }^{112,113,114,115,116}$ experimental conditions promoting the reverse reaction can deactivate $\mathrm{Pd}(\mathrm{II})$ precatalysts. This may occur when precatalyst activation by formal reduction of $\operatorname{Pd}(\mathrm{II})$ to $\mathrm{Pd}(0)$ is not fast enough as to avoid their coexistence in the reacting solution (Figures 3 and 7) or with substrates undergoing slow oxidative addition in the presence of large catalyst loadings. In the case of the Pd-allyl catalysts, the formation of dimers has been observed experimentally with different ancillary ligands. ${ }^{117,118,119}$

$\operatorname{Pd}(\mathrm{II})+\operatorname{Pd}(0)$ comproportionation to $\mathrm{Pd}(\mathrm{I})$ has a critical influence on catalysis, since it modulates the concentration of the active species. The role of Pd(I) dimers in the SMC with $\operatorname{Pd}(\mathrm{NHC})(\mathrm{Cl})\left(\mathrm{R}^{1}\right.$-allyl) precatalysts was explored by Hruszkewycz and co-workers for different $\mathrm{R}^{1}$ substituents at the $\mathrm{C}-1$ position of the allyl (Figure 7). ${ }^{120} \mathrm{~A}$ combination of experiments and computations showed that, due to steric effects, the syn and anti conformations of the $\mathrm{R}^{1}$-allyl are preferred by the $\mathrm{Pd}(\mathrm{II})$ monomers and $\mathrm{Pd}(\mathrm{I})$ dimers, respectively, for both the crotyl $\left(\mathrm{R}^{1}=\mathrm{Me}\right)$ and cinnamyl $\left(\mathrm{R}^{1}=\mathrm{Ph}\right)$ substituted-allyls, in agreement with the structures obtained by X-Ray crystallography. The calculations also predicted that the comproportionation reaction is exoergic, with $\Delta \mathrm{G}_{\mathrm{com}}<-13 \mathrm{kcal} \mathrm{mol}^{-1}$, in line with experiments showing the spontaneous formation of the dimers from the monomers, under both stoichiometric and catalytic conditions. $\Delta \mathrm{G}_{\mathrm{com}}$ was found to be sensitive to the nature of $\mathrm{R}^{1}$, which has a significant impact on the equilibrium constant of the isodesmic reaction shown in eq. 1.

$$
\mathrm{Pd}(\mathrm{NHC})(\mathrm{Cl})(\text { allyl })+\mathrm{Pd}_{2}(\mathrm{NHC})_{2}(\mu-\mathrm{Cl})\left(\mu-\mathrm{R}^{1} \text {-allyl }\right) \rightarrow \mathrm{Pd}(\mathrm{NHC})(\mathrm{Cl})\left(\mathrm{R}^{1} \text {-allyl }\right)+\mathrm{Pd}_{2}(\mathrm{NHC})_{2}(\mu-\mathrm{Cl})(\mu \text {-allyl })
$$


E.g., with $\mathrm{R}^{1}=\mathrm{Ph}$, the calculations yielded $\mathrm{K}_{\mathrm{eq}}\left(25^{\circ} \mathrm{C}\right)=1091$ for eq. (1), meanwhile the equivalent crossover experiment yielded $\mathrm{K}_{\mathrm{eq}}\left(25^{\circ} \mathrm{C}\right)>100$, with the reactants below the GC detection limits.
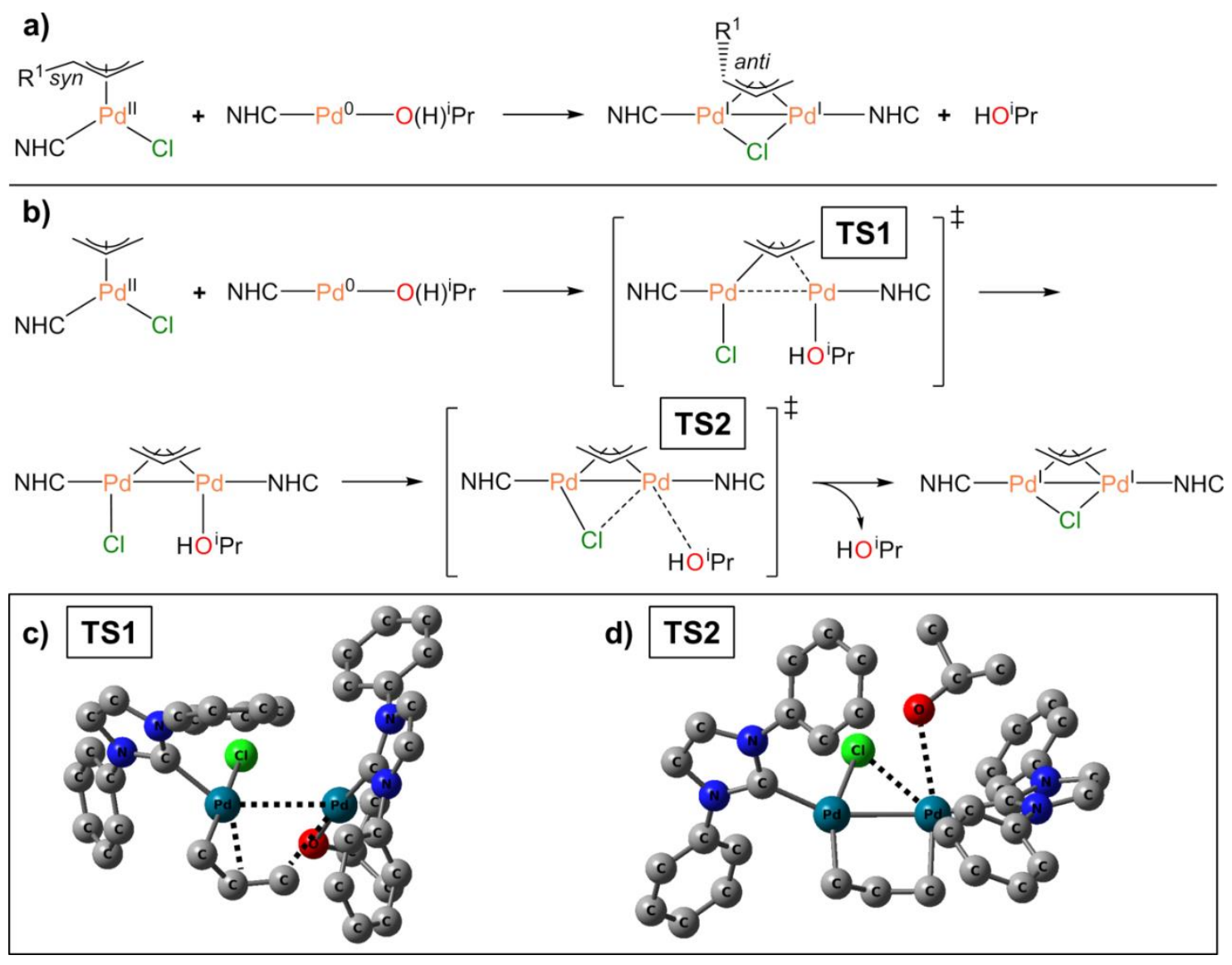

Figure 7. a) Dimerization of $\mathrm{Pd}(\mathrm{NHC})(\mathrm{Cl})\left(\mathrm{R}^{1}\right.$-allyl $)\left(\mathrm{R}^{1}=\mathrm{H}, \mathrm{Me}, \mathrm{Ph}\right)$; b) Reaction mechanism; c) DFT-optimized transition state for the shift of the ally ligand from $\eta^{3}$ - to $\mu$-coordination mode; d) DFT-optimized transition state for the shift of the chloride ligand from $\kappa^{1}$ - to $\mu$-coordination mode. The iso-propyl substituents of the NHC ligand were removed from the model. 
The good agreement between the experimental observations and the calculations supported the reliability of the DFT model, which was then used to determine the comproportionation mechanism (Figure 4). The $\mathrm{Pd}^{0}-\mathrm{NHC}$ active species is stabilized by the exoergic coordination of the solvent, iso-propanol, and it is thus better modelled as ${ }^{i} \operatorname{Pr}(\mathrm{H}) \mathrm{O}-\mathrm{Pd}^{0}-\mathrm{NHC}$. The reaction starts from this species with the addition of the $\mathrm{Pd}(\mathrm{II})$ precatalyst, yielding a dimer with a $\mathrm{Pd}(\mathrm{I})-\mathrm{Pd}(\mathrm{I})$ core stabilized by a bridging allyl ligand. In the transition state (TS1 in Figure 7), the allyl leans from the $\kappa^{1}$ - to the $\mu$-coordination mode as the Pd-Pd bond forms. In the second and last step, the same type of reaction takes place, with the chloride ligand evolving from $\kappa^{1}$ to $\mu$ in TS2, which triggers the decoordination of iso-propanol in the product. Alternative mechanisms involving paramagnetic $\operatorname{Pd}(\mathrm{I})$ species, $\operatorname{Pd}(0)$ anions and $\mathrm{Pd}(\mathrm{II})$ cations were excluded since they involved higher-energy pathways.

TS1 yielded the highest energy barrier of the reaction pathway $\left(\Delta \mathrm{G}_{\text {com }}^{\ddagger}\right.$ ). With the allyl, this barrier is low $\left(\Delta \mathrm{G}_{\text {com }}^{\ddagger}=9.6 \mathrm{kcal} \mathrm{mol}^{-1}\right)$, which is consistent with the observation of $\operatorname{Pd}(\mathrm{I})$ dimers in the catalytic experiments. With the $\mathrm{R}^{1}$-substituted allyls, the two metal centers become more separated at the transitions state; e.g., the forming Pd-Pd bond elongates by more than $0.4 \AA$. This structural distortion yields much higher energy barriers with the anti isomers of the crotyl $\left(\Delta \mathrm{G}_{\text {com }}^{\ddagger}=19.2 \mathrm{kcal} \mathrm{mol}^{-1}\right)$ and cinnamyl $\left(\Delta \mathrm{G}_{\text {com }}^{\ddagger}=18.3 \mathrm{kcal} \mathrm{mol}^{-1}\right)$ ligands. The substitution at the $\mathrm{R}^{1}$ position thus hampers the dimerization of the precatalyst with a significant increase in the energy barrier by $c a .7-10 \mathrm{kcal} \mathrm{mol}^{-1}$ (i.e., $10^{5-7}$ orders of magnitude slower rates). This effect was ascribed to steric effects involving the $\mathrm{R}^{1}$ substituent and the NHC ligand, on the basis of computational experiments varying the size of the NHC ligand. Upon replacing the imidazole phenyls by methyls, the barrier heightening caused by $\mathrm{R}^{1}$-substitution becomes less than $1 \mathrm{kcal}$ $\mathrm{mol}^{-1}$. Further, the calculations showed that the relative stability of the $\mathrm{L}-\mathrm{Pd}^{0}-\mathrm{NHC}$ active 
species, which depends on the nature of L (a coordinating solvent or substrate), also affects the comproportionation barrier.

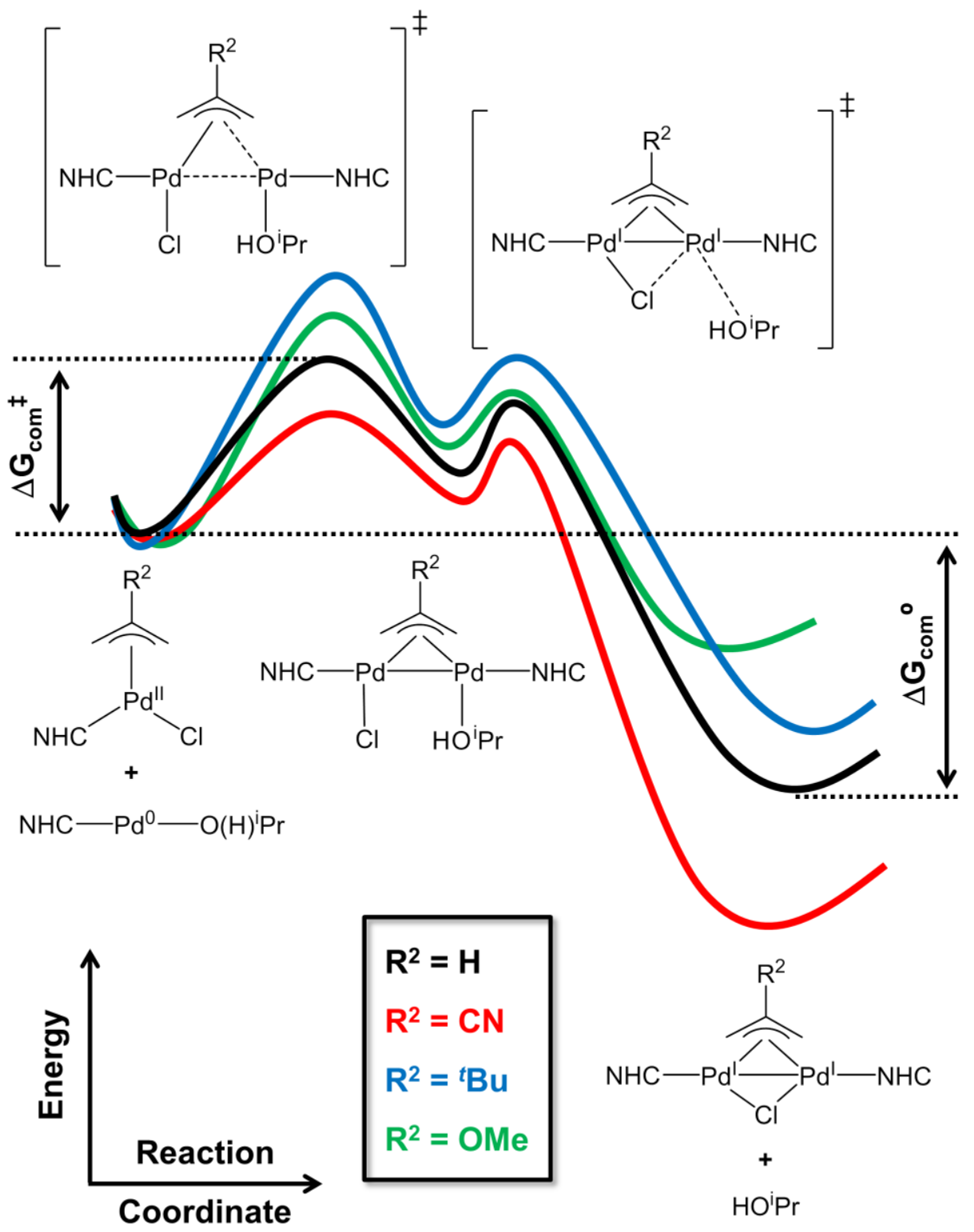

Figure 8. Energy profiles for the comproportionation mechanism with $\mathrm{Pd}(\mathrm{NHC})(\mathrm{Cl})\left(\mathrm{R}^{2}\right.$-allyl) precatalysts. 
Table 1. Reaction free energies $\left(\Delta \mathrm{G}_{\text {com }}\right)$ and free energy barriers $\left(\Delta \mathrm{G}^{\ddagger}\right.$ com $)$, in kcal $\mathrm{mol}^{-1}$, for comproportionation with the $\mathrm{Pd}(\mathrm{NHC})(\mathrm{Cl})\left(\mathrm{R}^{2}\right.$-allyl) precatalysts, as shown in Figure 8.

\begin{tabular}{ccc}
\hline $\mathrm{R}^{2}$ & $\Delta \mathrm{G}_{\mathrm{com}}$ & $\Delta \mathrm{G}^{\star}{ }_{\text {com }}$ \\
\hline $\mathrm{H}$ & -16.2 & 9.6 \\
$\mathrm{CN}$ & -24.1 & 6.2 \\
${ }^{t} \mathrm{Bu}$ & -11.4 & 17.5 \\
$\mathrm{OMe}$ & -8.5 & 14.1 \\
\hline
\end{tabular}

The influence of the stereoelectronic properties of the allyl substituent on dimerization was investigated in a more systematic manner for the $\mathrm{C}-2$ position $\left(\mathrm{R}^{2}\right) .{ }^{54} \mathrm{In}$ addition to $\mathrm{H}$, Me and $\mathrm{Ph}$, strong electron-donor $\left(\mathrm{R}^{2}=\mathrm{OMe}\right)$, -acceptor $\left(\mathrm{R}^{2}=\mathrm{CN}\right)$ and bulky $\left(\mathrm{R}^{2}={ }^{t} \mathrm{Bu}\right)$ substituents were considered. The impact of $\mathrm{R}^{2}$ on the energy profile of the comproportionation reaction was dramatic (Figure 8). Compared to $\mathrm{R}^{2}=\mathrm{H}\left(\Delta \mathrm{G}_{\mathrm{com}}^{\ddagger}=9.6 \mathrm{kcal} \mathrm{mol}^{-1}, \Delta \mathrm{G}_{\mathrm{com}}=-16.2 \mathrm{kcal} \mathrm{mol}^{-1}\right)$, $\mathrm{R}^{2}=\mathrm{CN}$ promoted the formation of the dimer by lowering its barrier to $\Delta \mathrm{G}^{\ddagger}$ com $=6.2 \mathrm{kcal} \mathrm{mol}^{-1}$ and by making it strongly exoergic, with $\Delta \mathrm{G}_{\mathrm{com}}=-24.1 \mathrm{kcal} \mathrm{mol}^{-1}$ (Table 1). The stabilization of the dimer by the cyanide group was ascribed to the strong $\operatorname{Pd}(d) \rightarrow$ allyl $\left(\pi^{*}\right)$ donor-acceptor interaction between the metal center and the bridging ligand, identified by NBO analysis (Figure 9). Consistent with this, the methoxide group had the opposite effect, destabilizing the dimer $\left(\Delta \mathrm{G}_{\mathrm{com}}=-8.5 \mathrm{kcal} \mathrm{mol}^{-1}\right)$. The steric bulk of the tert-butyl substituent hinders comproportionation, though its effect on the reaction thermodynamics is milder than that of the cyanide and methoxide substituents. Installed at the $\mathrm{R}^{2}$ position, the tert-butyl distorted the dimer structure, as shown by the Pd-Pd-IPr angle deviating from the ideal $180^{\circ}$ by $26.3^{\circ}\left(18.8^{\circ}\right.$ in the crystal). This is associated with the weak $\mathrm{CH} \cdots \pi$ and $\mathrm{CH} \cdots \mathrm{HC}$ interactions identified by NCIPLOT analysis (Figure 9). In general, there was a clear inverse correlation between the experimental activity of the precatalysts and the dimer stability predicted by the DFT 
calculations. Further, the DFT stabilities of the $\mathrm{Pd}_{2}(\mathrm{NHC})_{2}(\mu-\mathrm{Cl})\left(\mu-\mathrm{R}^{2}\right.$-allyl) dimers were in agreement with crossover experiments based on eq. (2), which yielded $\mathrm{K}_{\mathrm{eq}}>100$ at $40{ }^{\circ} \mathrm{C}$ for $\mathrm{R}^{2}$ $=\mathrm{CN}$.

$\mathrm{Pd}(\mathrm{NHC})(\mathrm{Cl})($ allyl $)+\mathrm{Pd}_{2}(\mathrm{NHC})_{2}(\mu-\mathrm{Cl})\left(\mu-\mathrm{R}^{2}\right.$-allyl $) \rightarrow \mathrm{Pd}(\mathrm{NHC})(\mathrm{Cl})\left(\mathrm{R}^{2}\right.$-allyl $)+\mathrm{Pd}_{2}(\mathrm{NHC})_{2}(\mu-\mathrm{Cl})(\mu$-allyl $)$

These studies showed that the dimerization thermochemistry and kinetics depend on the nature of the allyl $\mathrm{R}^{1}$ and $\mathrm{R}^{2}$ substituents, which can be used to enhance catalysis by preventing comproportionation. This added a new perspective to the hypothesis of Nolan, which suggested that the increasing $\mathrm{R}^{1}=\mathrm{H}<\mathrm{Me}<\mathrm{Ph}$ efficiency of the $\mathrm{Pd}(\mathrm{II})$ precatalysts was due to the weakening of the Pd-allyl bond favoring activation to $\operatorname{Pd}(0) \cdot{ }^{24}$ Hence, the substituents on the allyl ligand can be exploited in catalyst design to modulate both precatalyst activation and catalyst deactivation.

a)

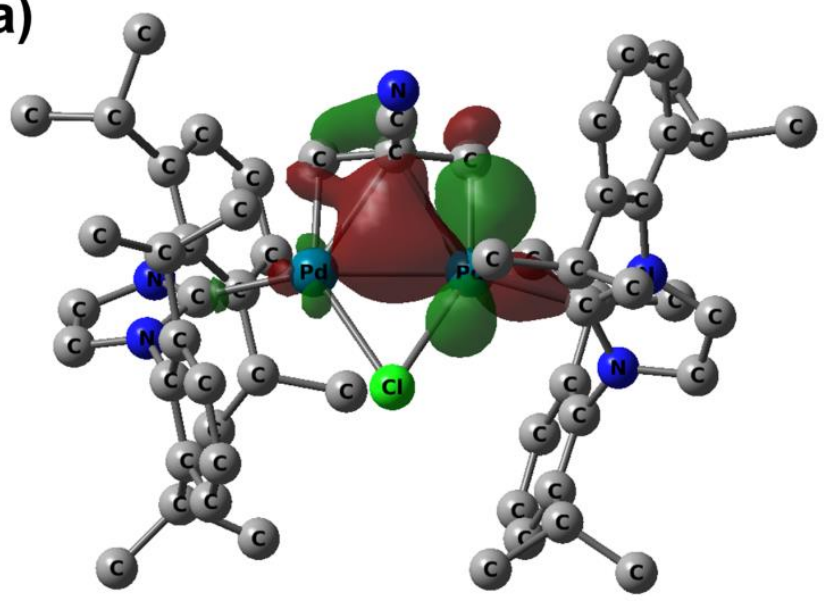

b)

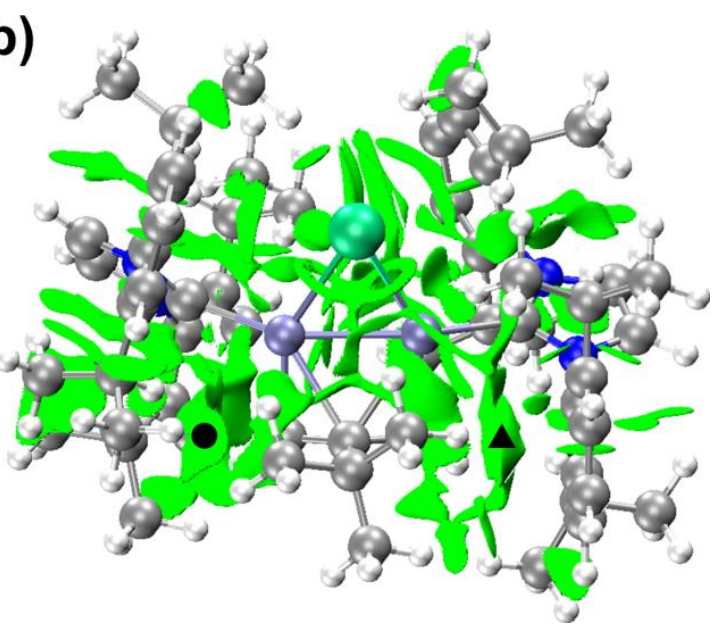

Figure 9. Electronic structure of the $\operatorname{Pd}_{2}(\operatorname{IPr})_{2}(\mu-\mathrm{Cl})\left(\mu-\mathrm{R}^{2}\right.$-allyl) dimers. a) Donor-acceptor $\operatorname{Pd}(d) \rightarrow \operatorname{allyl}\left(\pi^{*}\right)$ interaction from NBO6 analysis $\left(\mathrm{R}^{2}=\mathrm{CN}\right)$; b) Weak interactions, including $\mathrm{CH}^{\cdots} \pi(\boldsymbol{\Delta})$ and $\mathrm{CH} \cdots \mathrm{HC}(\bullet)$ contacts between the NHC ligand and $\mathrm{R}^{2}={ }^{t} \mathrm{Bu}$, from NCIPLOT analysis. 

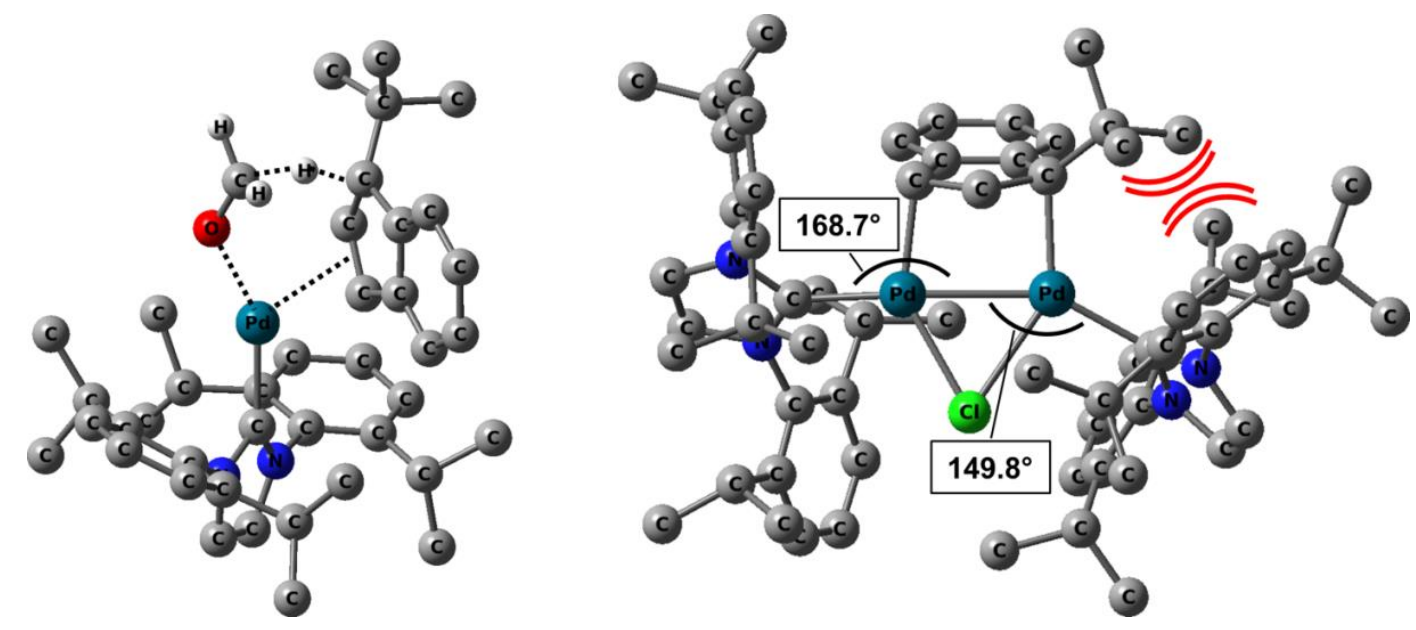

Figure 10. DFT-optimized geometries of the H-shift transition state (hydrogen shift mechanism; left) and Pd(I) dimer (right) in the catalytic system combining the 1 - $^{\mathrm{t}} \mathrm{Bu}-\mathrm{indenyl}$ and IPr ligands.

As with the allyl precatalyst, the activation of $\operatorname{Pd}(\operatorname{IPr})(\mathrm{Cl})(\mathrm{Ind})$ (Figure 10) involved the nucleophilic attack of the indenyl ligand to a $\mathrm{H}$ atom of the Pd-bound alkoxide (Figure 4). The attacking C-1 position can be easily functionalized with different organic groups. Melvin and coworkers identified tert-butyl as an optimal group due to its twofold enhancing effect on catalysis: ${ }^{28}$ 1) due to electron-donation, it promoted nucleophilic attack in the H-shift transition state (Figure 4) and 2) due to steric bulk, it prevented dimerization by comproportionation (Figure 7). The positive effect of electron-donation was reflected on the activation barrier, which was lowered from $\Delta \mathrm{G}^{\dagger} \mathrm{HS}=21.7 \mathrm{kcal} \mathrm{mol}^{-1}$, with the indenyl ligand, to $\Delta \mathrm{G}^{\dagger} \mathrm{HS}=19.8 \mathrm{kcal} \mathrm{mol}^{-1}$, with the $1{ }^{-} \mathrm{Bu}$-indenyl ligand. The positive effect of steric hindrance was reflected on the thermochemistry computed for the comproportionation reaction (Figure 7), which, with the 1${ }^{t} \mathrm{Bu}$-indenyl ligand, became endoergic $\left(\Delta \mathrm{G}_{\mathrm{com}}=2.6 \mathrm{kcal} \mathrm{mol}^{-1}\right)$. The steric effects caused the distortion of the $\mathrm{C}_{\mathrm{IPr}}-\mathrm{Pd}-\mathrm{Pd}-\mathrm{C}_{\mathrm{IPr}}$ moiety, which deviated from its ideal linear arrangement, primarily on the side occupied by the tert-butyl substituent $\left(\theta=149.8^{\circ}\right)$. In line with this, the comproportionation free energy shifted from exoergic to endoergic in a gradual manner as the 
steric bulk at the $\mathrm{C}-1$ position was increased; i.e. $\Delta \mathrm{G}_{\mathrm{com}}=-9.4(\mathrm{H}),-2.0(\mathrm{Me}), 1.8\left({ }^{i} \operatorname{Pr}\right)$ and 2.6 $\left({ }^{\mathrm{t}} \mathrm{Bu}\right) \mathrm{kcal} \mathrm{mol}^{-1}$. Experiments proved that combining fast activation with endoergic dimerization in the off-cycle part of the mechanism (Figure 3) yields exceptional results. The $\operatorname{Pd}(\mathrm{IPr})(\mathrm{Cl})(1$ $\left.{ }^{t} \mathrm{Bu}-\mathrm{Ind}\right)$ precatalyst, which is now commercially available, showed high activity with small catalyst loadings under mild reaction conditions and broad scope in different cross-coupling reactions (Suzuki-Miyaura and Buchwald-Hartwig), including challenging substrates ${ }^{121}$ (e.g., heterocyclic boronic acids, upon replacing the IPr ligand by XPhos).

Seechurn and co-workers reported that replacing $\mathrm{R}^{1}=\mathrm{H}$ by $\mathrm{Me}$ in $\mathrm{Pd}\left(\mathrm{R}^{1}\right.$-allyl)(Cl)(L) also destabilizes the dimer with $\mathrm{L}=$ phosphine. $E$. $g$., with $\mathrm{L}=\mathrm{Q}-\mathrm{Phos}$ and $\mathrm{P}\left({ }^{t} \mathrm{Bu}\right)_{3}$, dimeric species were only observed with $\mathrm{R}^{1}=\mathrm{H} .{ }^{98}$ Further, by using biarylphosphine-based ligands, such as $\mathrm{L}=$ BrettPhos, ${ }^{t} \mathrm{BuXPhos}$ and ${ }^{t} \mathrm{BuBrettPhos}$, the Colacot group was able to prevent the formation of the dimer in all cases, including $\mathrm{R}^{1}=\mathrm{H} .{ }^{122}$ These precatalysts showed high activity for challenging cross-coupling reactions, which was ascribed to both fast catalyst activation and the exclusion of the comproportionation pathway. Proutiere and co-workers related the stability of dinuclear $\left[\left(\mathrm{PR}_{3}\right) \mathrm{Pd}(\mu-\mathrm{Br})\right]_{2}$ species with the cone angle of the phosphine ligand. ${ }^{123} E$. $g$., while phosphines with cone angles $>175^{\circ}$, such as $\mathrm{P}^{t} \mathrm{Bu}_{3}$ and $\mathrm{P}\left({ }^{i} \mathrm{Pr}\right)\left({ }^{t} \mathrm{Bu}\right)_{2}$, yielded stable dinuclear species, $\mathrm{PCy}_{3}$, with a cone angle of $170^{\circ}$, did not. Bulky carbenes were also used to boost the reactivity of Pd-cinnamyl precatalysts. ${ }^{124}$ 


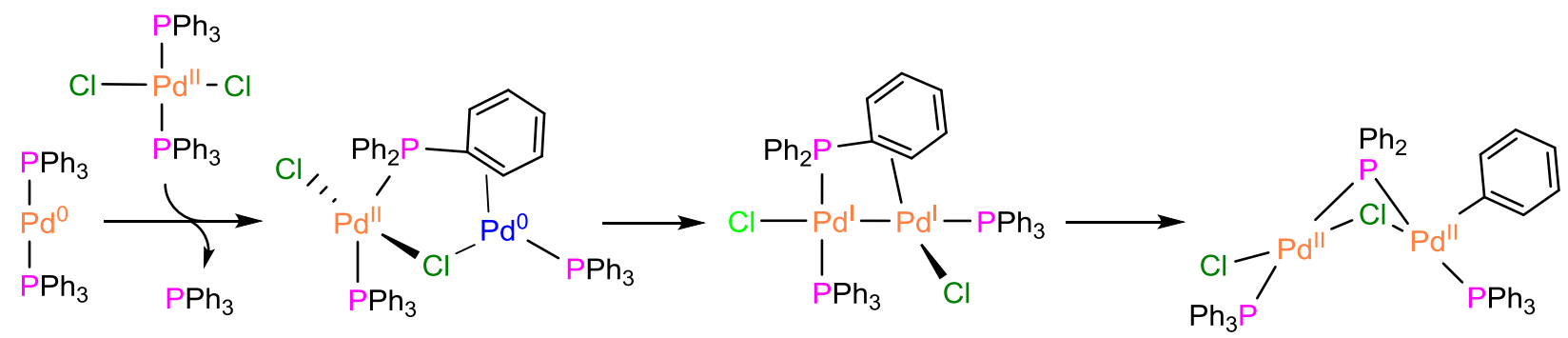

Figure 11. First steps in the trimerization of the $\mathrm{Pd}(\mathrm{Cl})_{2}\left(\mathrm{PPh}_{3}\right)_{2}$ precatalyst, including the comproportionation to $\mathrm{Pd}(\mathrm{I})$ and the oxidative of the phosphine $\mathrm{P}-\mathrm{C}$ bond.

The use of $\pi$-acidic isocyanate ligands in $\mathrm{Pd}(\mathrm{Cl})($ allyl $)(\mathrm{L})\left(\mathrm{L}=\mathrm{Ar}^{\mathrm{Dipp} 2} \mathrm{CN}\right)$ was shown to promote the formation of highly stable dimers with both chloride and alkoxide bridging ligands. ${ }^{125}$ Furthermore, the dinuclear dimer with $\mu-\mathrm{O}^{i} \operatorname{Pr}$ is thermally unstable and decomposes to a trinuclear cluster, i.e. triangulo- $\mathrm{Pd}_{3}\left(\eta^{2} \text {-Dipp- } \mu-\mathrm{CNAr}\right)_{3}$, which acts as a source of monoligated $\mathrm{Pd}^{0}$ catalyst for Suzuki-Miyaura reactions. In this system, the isocyanate ligand does not decompose during the formation of the trimer, allowing for the recovery of all catalyst. However, formation of trimers may involve ligand decomposition, as observed in the Bora-Negishi reaction using the $\mathrm{Pd}(\mathrm{Cl})_{2}\left(\mathrm{PPh}_{3}\right)_{2}$ precatalyst. $^{126}$ In this case, the amount of $\left[\left(\mathrm{Ph}_{3} \mathrm{P}\right)_{3} \mathrm{Pd}_{3}\left(\mu-\mathrm{PPh}_{2}\right)_{2}(\mu-\mathrm{Br})\right]^{+}$trimer formed was very sensitive to the concentration of the zinc reagent, varying from $60 \%$, with 0.5 equivalents of $\mathrm{Zn}$, to $<1 \%$, with 2.5 equivalents. This observation was rationalized by means of DFT calculations on the reaction mechanism yielding the trimer, which starts with the comproportionation of the $\operatorname{Pd}(0)$ active species with the $\operatorname{Pd}(\mathrm{II})$ precatalyst, followed by the oxidative addition of the phosphine $\mathrm{P}-\mathrm{C}$ bond (Figure 11). Interestingly, $\left[\mathrm{PPh}_{4}\right]^{+}$was observed as a side-product of the trimer formation. The oxidation of the phosphine was also observed by Colacot and Schoenebeck during the formation of $\operatorname{Pd}(\mathrm{I})$ dimers from $\mathrm{Pd}(\operatorname{cod})(\mathrm{Br})_{2}$ and phosphines. ${ }^{127}$ In this case, the addition of 6 equivalents of $\mathrm{P}^{t} \mathrm{Bu}_{3}$ 
to the $\mathrm{Pd}(\mathrm{II})$ precatalyst led to the formation of dinuclear $\mathrm{Pd}$ complexes, including $\left[\mathrm{Pd}_{2}(\mu-\mathrm{Br})_{2}\left(\mathrm{PtBu}_{3}\right)_{2}\right]$ and $\left[\mathrm{Pd}_{2} \mathrm{Br}_{6}\right]\left[\mathrm{BrP}^{t} \mathrm{Bu}_{3}\right]$. The formation of the dimeric species was prevented by increasing the amount of phosphine to a large excess of 18 equivalents. The mechanism proposed for this reaction, based both on experiments and DFT thermodynamics, involves the participation of the $\mathrm{Pd}\left(\mathrm{P}^{t} \mathrm{Bu}\right)_{2}(\mathrm{Br})_{2}$ and $\mathrm{Pd}_{2}(\mu-\mathrm{Br})_{2}(\mathrm{Br})\left(\mathrm{P}^{t} \mathrm{Bu}_{3}\right)$ complexes as intermediates.

\section{OFF-CYCLE APPROACH TO NICKEL CATALYSTS}

Replacing palladium by nickel in catalytic cross-couplings ${ }^{128,129,130,131,132,133,134,135}$ could make these reactions more sustainable and cost-effective, due to the lower price of the latter metal. Nickel catalysts are capable of activating aryl sulfamates, ${ }^{136,137,138}$ which are especially appealing because they can be diversified by selective functionalization prior to cross-coupling. ${ }^{139,140,141}$ However, nickel catalysts also have disadvantages - the conditions required to achieve high yields are harsher than those of palladium, including the need for higher temperatures and catalyst loadings. Further, compared to palladium, tackling these pitfalls from a mechanistic perspective is more difficult because nickel involves more complicated reaction pathways. 


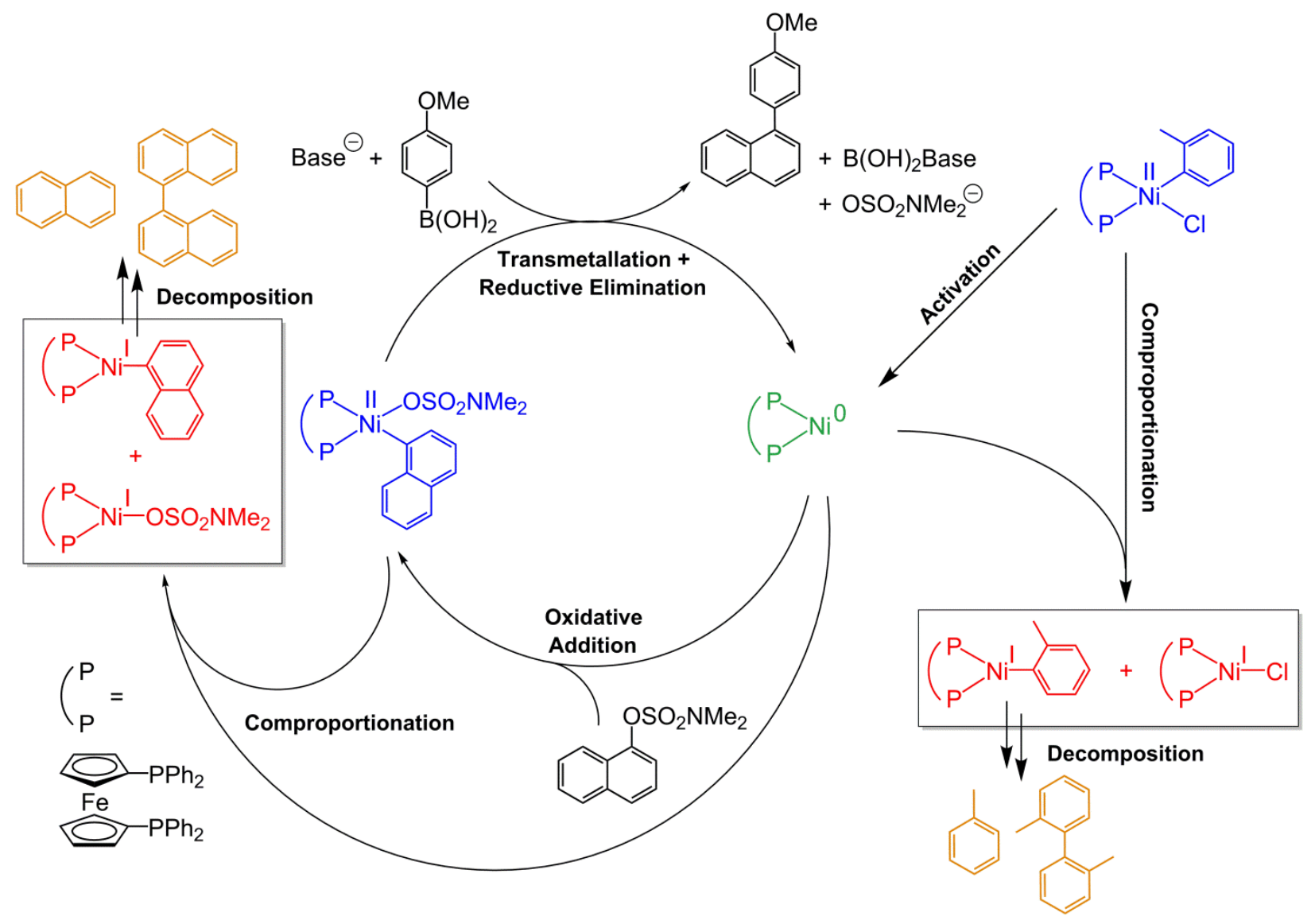

Figure 12. On- and off-cycle steps in the nickel-catalyzed Suzuki-Miyaura coupling of aryl sulfamates. Sideproducts and $\mathrm{Ni}(0), \mathrm{Ni}(\mathrm{I})$ and $\mathrm{Ni}(\mathrm{II})$ species are highlighted in orange, green, red and blue, respectively.

Nickel can activate bonds by both homolytic and heterolytic mechanisms. These can yield several catalytic intermediates in the $\mathrm{Ni}(0), \mathrm{Ni}(\mathrm{I})$ and $\mathrm{Ni}(\mathrm{II})$ oxidation states, which can be either on-cycle or off-cycle. These mechanistic features were explored by Guard, Beromi and coworkers for the SMC of aryl sulfamates (Figure 12) ${ }^{61,142}$ Experiments first showed that $\mathrm{Ni}(\mathrm{II})$ and $\mathrm{Ni}(0)$ precatalysts supported by the dppf (1,1'-bis(diphenylphosphino)-ferrocene) ligand yielded significant amounts of $\mathrm{Ni}(\mathrm{I})$ complexes $^{143}$ detected by EPR spectroscopy, though the postulated reaction mechanism was based on a $\mathrm{Ni}(0) / \mathrm{Ni}(\mathrm{II})$ couple. After 4-12 hours of catalysis, $22-61 \%$ of the total molar concentration of nickel was in the $\mathrm{Ni}(\mathrm{I})$ oxidation state; e.g. $\mathrm{Ni}(\mathrm{dppf})(\mathrm{Cl})$. Interestingly, $\mathrm{Ni}(\mathrm{I})$ species originated from both $\mathrm{Ni}(\mathrm{II})$ and $\mathrm{Ni}(0)$ precatalysts; e.g. 
$\mathrm{Ni}(\mathrm{dppf})(\mathrm{Cl})(o$-tolyl) and $\mathrm{Ni}(\mathrm{dppf})($ ethylene), respectively. In the latter case, the anionic ligand of the $\mathrm{Ni}(\mathrm{I})$ species must come from the on-cycle activation of the organic substrates. Further, experiments showed that the formation of the $\mathrm{Ni}(\mathrm{I}) \mathrm{Ni}(\mathrm{dppf})(\mathrm{Cl})$ complex is detrimental, because yields were lower than $1 \%$ when it was used as precatalyst under the optimized conditions. In line with this, $\mathrm{Ni}(\mathrm{dppf})(\mathrm{Cl})$ was also detected and identified as a non-productive off-cycle species by Yin and co-workers in the coupling of substituted aryl chlorides to $\left(\mathrm{Me}_{4} \mathrm{~N}\right) \mathrm{SCF}_{3} .{ }^{144}$ In contrast with $\mathrm{Ni}(\mathrm{dppf})(\mathrm{Cl}), \mathrm{Ni}(\mathrm{dppf})(\mathrm{Cl})(o$-tolyl) is a highly active precatalyst, achieving yields over $99 \%$. This complex is activated by transmetallation and reductive elimination yielding the $\mathrm{Ni}(0) \mathrm{Ni}(\mathrm{dppf})$ species. Ni(dppf) starts the catalytic cycle by oxidative addition, but can also react with the $\mathrm{Ni}(\mathrm{II})$ precatalyst to yield $\mathrm{Ni}(\mathrm{I})$ species by the comproportionation reaction shown in eq. 3.

$$
\mathrm{Ni}(\text { dppf })(\mathrm{Cl})(o \text {-tolyl })+\mathrm{Ni}(\mathrm{dppf}) \rightarrow \mathrm{Ni}(\mathrm{dppf})(\mathrm{Cl})+\mathrm{Ni}(\mathrm{dppf})(o \text {-tolyl })
$$

In contrast with $\mathrm{Ni}(\mathrm{dpp} f(\mathrm{Cl})$, the other $\mathrm{Ni}(\mathrm{I})$ comproportionation product in eq. (3), $\mathrm{Ni}(\mathrm{dppf})(o$-tolyl), is unstable, undergoing decomposition to toluene and biphenyl side-products detected experimentally (Figure 12). Further, comproportionation may also involve other Ni(II) species, including on-cycle intermediates. This hypothesis was supported for the naphthylsulfamate oxidative addition product, for which naphthalene and dinaphthalene side-products were also observed.

The mechanism shown in Figure 12 was proposed on the basis of these experimental data. The productive part of the mechanism involves a $\mathrm{Ni}(0) / \mathrm{Ni}(\mathrm{II})$ catalytic cycle analogous to that postulated for palladium (Figure 3). The off-cycle part includes the reaction of the $\mathrm{Ni}(0)$ active species with either the $\mathrm{Ni}$ (II) precatalyst or the $\mathrm{Ni}(\mathrm{II})$ oxidative addition product. Both processes 
are detrimental, since the resulting $\mathrm{Ni}(\mathrm{I})$ species are either inactive or undergo decomposition. In this framework, the comproportionation reactions connecting the on- and off-cycle components of the mechanism play a key role. DFT calculations showed that eq. (3) can be modeled as a singlet-to-triplet spin crossover with a low-energy MECP (minimum energy crossing point) at $6.4 \mathrm{kcal} \mathrm{mol}^{-1}$ above reactants. The process starts with the spontaneous aggregation of the $\mathrm{Ni}(\mathrm{dppf})(\mathrm{Cl})(\mathrm{o}-$ tolyl $)$ and $\mathrm{Ni}(\mathrm{dppf})$ complexes into a dimer $\left(\Delta \mathrm{G}_{\mathrm{dim}}=-6.2 \mathrm{kcal} \mathrm{mol}^{-1}\right)$. This species is stabilized by an unusual combination of two bridging interactions involving both the chloride $(\mathrm{d}(\mathrm{Ni}-\mathrm{Cl})=2.56 \AA)$ and one of the dppf ligands (Figure 13). The latter interaction is similar to that observed in some palladium dimer precatalysts ${ }^{145,146}$ and consists of a $\pi \eta^{2}$-bond between one of the nickel atoms and a phenyl ring of the dppf ligand bound to the other nickel $(\mathrm{d}(\mathrm{Ni}-\mathrm{C})=2.05$ and $2.09 \AA)$. This structure converged into a singlet ground state, in which the $\mathrm{Ni}(\mathrm{II})$ and $\mathrm{Ni}(0)$ oxidation states were easily assigned on the basis of the formal charge of the ligands bound to each metal center. The DFT-reoptimization of this species in the triplet state yielded a different structure of similar energy $\left(1.2 \mathrm{kcal} \mathrm{mol}^{-1}\right.$ above the singlet). In this structure, both metal centers were $\mathrm{Ni}(\mathrm{I})$; one bound to the $o$-tolyl ligand and the other to the $\mathrm{Cl}$. There is also a weak $\mu-\mathrm{Cl}$ bridge $(\mathrm{d}(\mathrm{Ni}-\mathrm{Cl})=2.42 \AA)$, which undergoes exoergic dissociation into the $\mathrm{Ni}(\mathrm{I})$ monomers $\left(\Delta \mathrm{G}_{\mathrm{dis}}=-4.8 \mathrm{kcal} \mathrm{mol}^{-1}\right)$. The overall energy profile is rather flat, giving access to both the detrimental $\mathrm{Ni}(\mathrm{I})$ species and the productive $\mathrm{Ni}(0)$ species, which enters the catalytic cycle through the moderate energy barrier associated with the oxidative addition of the sulfamate $\left(\Delta \mathrm{G}^{\ddagger} \mathrm{OA}=17.5 \mathrm{kcal} \mathrm{mol}{ }^{-1}\right)$. The resulting $\mathrm{Ni}(\mathrm{II})$ intermediate can also undergo comproportionation through a similar pathway involving the sulfamate as bridging-ligand, though, in this case, the spin crossover barrier is lower, with the MECP at $1.6 \mathrm{kcal} \mathrm{mol}^{-1}$. As in the case of palladium, the comproportionation mechanism found for nickel had an associative 
nature. This suggests that catalysis should be enhanced by bulky ligands mitigating the formation of $\mathrm{Ni}(\mathrm{I})$ species.

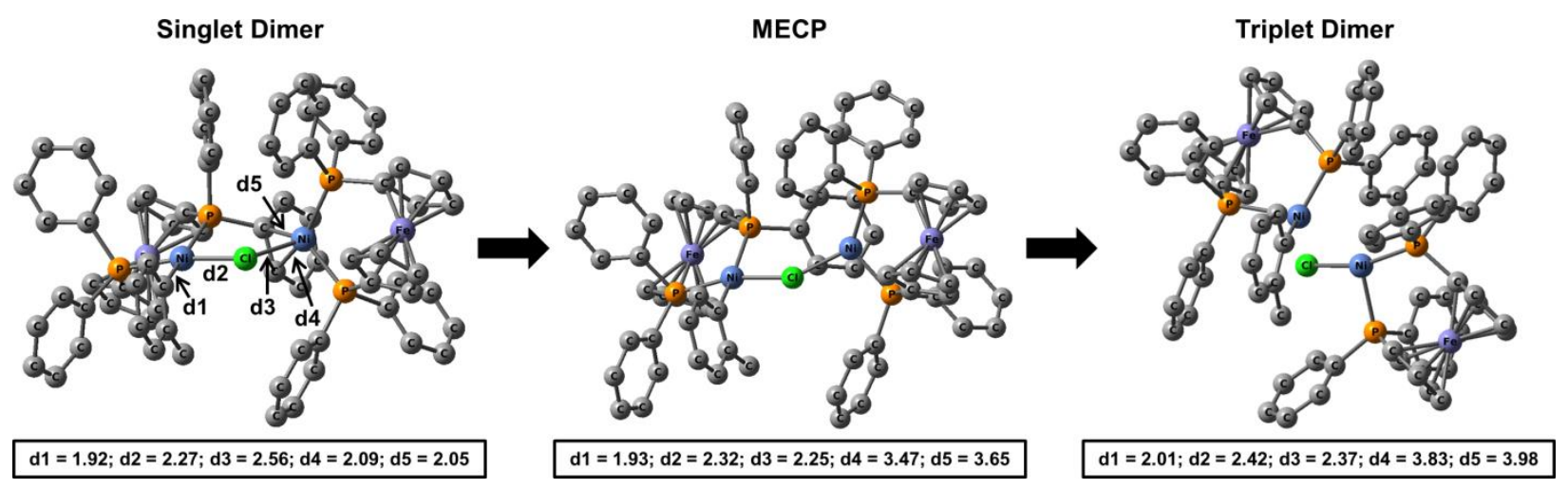

Figure 13. Key structures in the comproportionation of $\mathrm{Ni}^{\mathrm{II}}(\mathrm{dppf})(o$-tolyl $)(\mathrm{Cl}) \cdots \mathrm{Ni}^{0}(\mathrm{dppf})$ to $\mathrm{Ni}^{\mathrm{I}}(\mathrm{dppf})(o$-tolyl $) \cdots \mathrm{Ni}^{\mathrm{I}}(\mathrm{dppf})(\mathrm{Cl})$ by singlet-to-triplet spin crossover. Distances are given in $\AA$.

In a combined experimental/theoretical study, Kalvet and co-workers also reported the formation of $\mathrm{Ni}(\mathrm{I})$ species in the $\mathrm{SCF}_{3}$-coupling to aryl bromides and iodides catalyzed by $\mathrm{Ni}(\mathrm{dppf})(\mathrm{cod}){ }^{147}$ They postulated a comproportionation mechanism involving the $\mathrm{Ni}(\mathrm{II})$ oxidative addition product, $\mathrm{Ni}(\mathrm{dppf})(\mathrm{Ph})(\mathrm{X})$. Ni(I) species were isolated and characterized by X-Ray diffraction revealing monomeric and dimeric structures for bromide and iodide, respectively. DFT calculations showed that $\mathrm{Ni}(\mathrm{I})$ formation is exoergic for both halogens to an extent similar to that of the chloride. The authors also identified another off-cycle reaction; namely, the $\beta-\mathrm{F}$ elimination from the transmetallation $\mathrm{Ni}(\mathrm{II}) \mathrm{Ni}(\mathrm{dppf})(\mathrm{Ph})\left(\mathrm{SCF}_{3}\right)$ intermediate (Figure 14). The energy barrier of this process is rather large $\left(\Delta \mathrm{G}^{+} \beta\right.$-FE $\left.=23.7 \mathrm{kcal} \mathrm{mol}^{-1}\right)$ and higher than that of the reductive elimination yielding the $\mathrm{Ph}-\mathrm{SCF}_{3}$ product $\left(\Delta \mathrm{G}_{\mathrm{RE}}^{\dagger}=16.2 \mathrm{kcal} \mathrm{mol}^{-1}\right)$. However, $\beta-\mathrm{F}$ elimination is much faster with the $\mathrm{Ni}(\mathrm{I})$ off-cycle species, $\mathrm{Ni}(\mathrm{dppf})\left(\mathrm{SCF}_{3}\right)$, which yielded a competitive barrier $\left(\Delta \mathrm{G}^{\ddagger} \beta\right.$-FE $\left.=20.6 \mathrm{kcal} \mathrm{mol}^{-1}\right)$. Further, the side-product of this reaction, $\mathrm{SCF}_{2}$, deactivates the precatalyst by forming a $\eta^{2}$-bond between the $\mathrm{C}-\mathrm{S}$ moiety and the metal center. 
The resulting $\mathrm{Ni}(0) \mathrm{Ni}(\mathrm{dppf})\left(\mathrm{SCF}_{2}\right)$ complex was characterized by both ${ }^{31} \mathrm{P}-\mathrm{NMR}$ spectroscopy and X-Ray crystallography. This deleterious reaction was excluded by replacing dppf by dmbpy (4,4'-dimethoxybipyridine), which is a $\kappa^{2}-\mathrm{N}$ chelating ligand causing the heightening of the $\beta$-F elimination barrier to $>23 \mathrm{kcal} \mathrm{mol}^{-1}$ from both the on-cycle $\mathrm{Ni}(\mathrm{II})$ and off-cycle $\mathrm{Ni}(\mathrm{I})$ species.

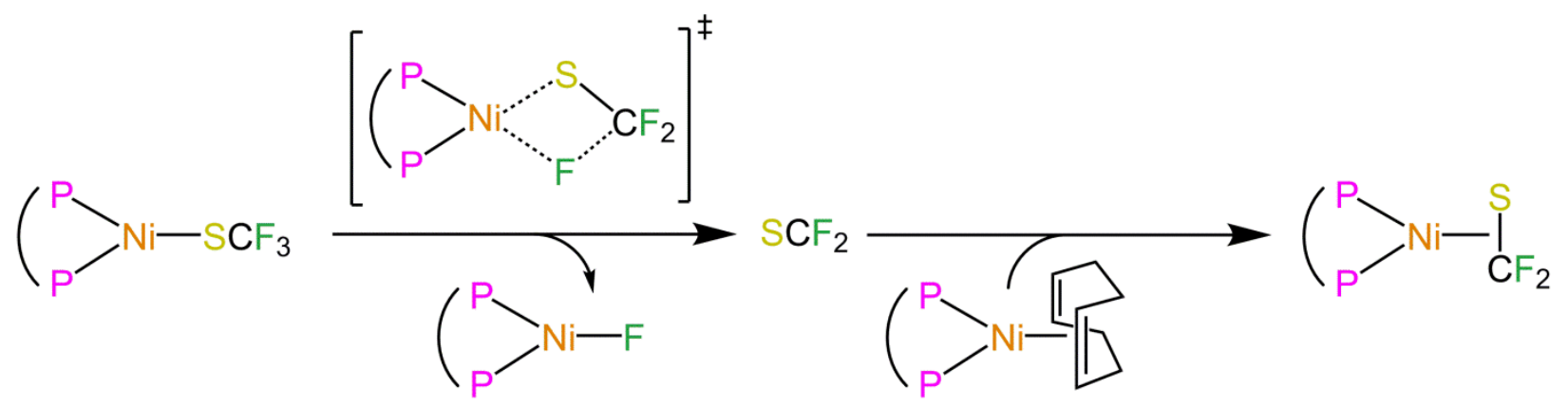

Figure 14. $\beta$-F elimination from the $\mathrm{SCF}_{3}$-bound $\mathrm{Ni}(\mathrm{I})$-dppf complex (left) and deactivation of the cod-bound $\mathrm{Ni}(0)$-dppf catalyst by coordination of the resulting $\mathrm{SCF}_{2}$ product (right).

The formation of off-cycle $\mathrm{Ni}(\mathrm{I})$ species from the oxidative addition product was also explored by Bajo and co-workers. ${ }^{148}$ They performed systematic kinetic studies showing the dependence of the oxidative addition rate on the nature of $\mathrm{X}$ in the $p-\mathrm{X}, \mathrm{CF}_{3}-\mathrm{C}_{6} \mathrm{H}_{4}$ electrophile $(\mathrm{X}=\mathrm{F}, \mathrm{Cl}, \mathrm{Br}$, I, OMe, $\mathrm{CO}_{2}{ }^{\mathrm{t}} \mathrm{Bu}, \mathrm{CO}_{2} \mathrm{NEt}_{2}, \mathrm{CO}_{3} \mathrm{Et}, \mathrm{SO}_{3} \mathrm{CF}_{3}, \mathrm{SO}_{3}-p$-tol and $\mathrm{SO}_{3} \mathrm{NMe}_{2}$ ). The reaction starts from the $\mathrm{Ni}(0) \mathrm{Ni}(\mathrm{dppf})(\mathrm{cod})$ complex by a ligand exchange pre-equilibrium replacing cod by $p$ - $(\mathrm{X})\left(\mathrm{CF}_{3}\right) \mathrm{C}_{6} \mathrm{H}_{4}$. The $\mathrm{Ni}(\mathrm{II})$ product, $\mathrm{Ni}(\mathrm{dppf})(\mathrm{X})\left(p-\mathrm{CF}_{3}-\mathrm{C}_{6} \mathrm{H}_{4}\right)$, yields $\left(p-\mathrm{CF}_{3}-\mathrm{C}_{6} \mathrm{H}_{4}\right)_{2}$ biaryls, resulting from the comproportionation of $\mathrm{Ni}(\mathrm{II})$ and $\mathrm{Ni}(0)$, followed by decomposition of the $\mathrm{Ni}(\mathrm{I})-\left(p-\mathrm{CF}_{3}-\mathrm{C}_{6} \mathrm{H}_{4}\right)$ product. In addition to these species, $\mathrm{Ni}(\mathrm{I}) \mathrm{Ni}(\mathrm{dppf})(\mathrm{X})$ complexes were formed and characterized by EPR spectroscopy. The steric bulk at the ortho position of the aryl ligand had a strong influence on the outcome of this reaction. Catalytic experiments also showed that the propensity towards $\mathrm{Ni}(\mathrm{I})$ formation correlates with the homocoupling product yields. 


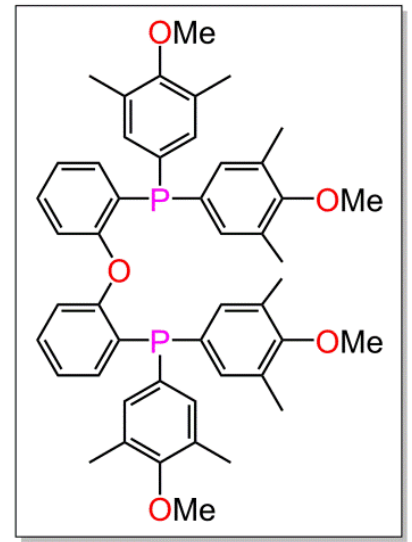

DMM-DPEPhos

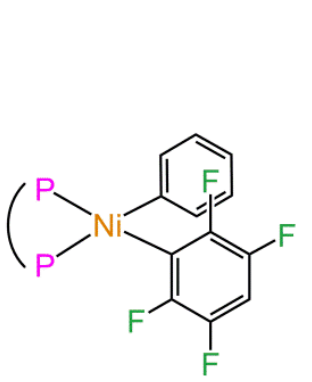

in-cycle

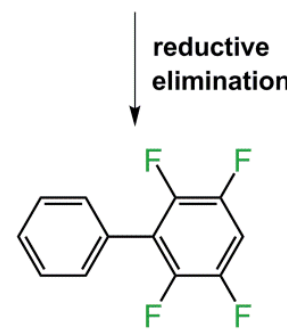

desired product

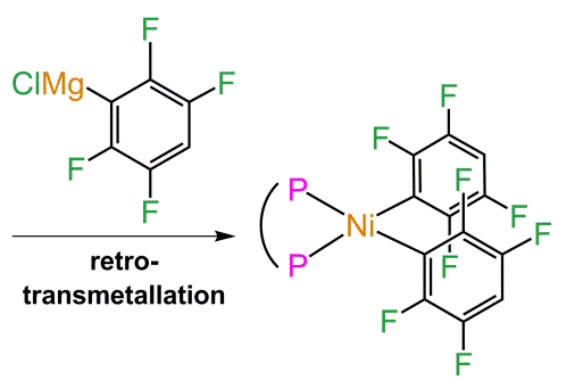

off-cycle

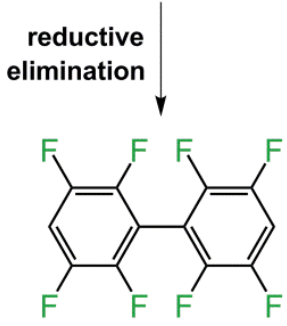

undesired product

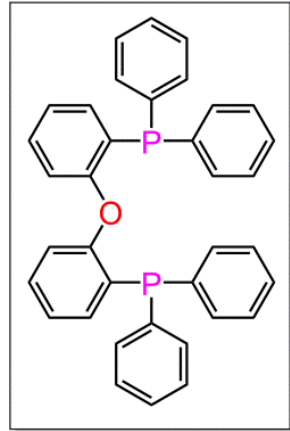

DPEPhos

Figure 15. On- and off-cycle coupling products from transmetallation and reductive elimination.

Another escape point in the catalytic cycle is the transmetallation step. An experimental study by Wang and co-workers on the nickel-catalyzed Kumada-Tamao-Corriu (KTC) reaction showed that off-cycle species can originate from an unusual retro-transmetallation step, ${ }^{149}$ which had also been observed with palladium complexes. ${ }^{150,151,152}$ The KTC coupling was used to transform Grignard reagents into polyfluorinated biaryl products of high interest in materials science. The on-cycle transmetallation yields a $\mathrm{Ni}(\mathrm{II})$ intermediate with two aryl ligands $\left(\mathrm{C}_{6} \mathrm{H}_{5}\right.$ and 2,3,5,6$\mathrm{C}_{6} \mathrm{HF}_{4}$ ) bound to the metal center (Figure 15). The reductive elimination of the product from this intermediate was shown to compete with a second transmetallation replacing the $\mathrm{C}_{6} \mathrm{H}_{5}$ ligand by an extra 2,3,5,6- $\mathrm{C}_{6} \mathrm{HF}_{4}$. The resulting off-cycle intermediate was characterized by X-Ray diffraction and its formation was proven to be detrimental, since it decreased both the yield and selectivity of the overall reaction. The study showed that catalysis was enhanced by inhibiting the formation of this species, which was achieved with the DMM-DPEPhos ligand resulting from 
the functionalization of the original DPEPhos ligand ((oxydi-2,1phenylene)bis(diphenylphosphine)) with methyl and methoxide substituents.

The value of metal-catalyzed cross-coupling reactions increases with functional group tolerance, since it expands product scope. However, this desirable feature is often challenged by sidereactions in which the functionals groups of the substrate react with the metal center causing catalyst deactivation. Dürr and co-workers addressed this issue by developing a protocol in which compatible functional groups were identified based on comparing energy barriers computed with a DFT method (Figure 16). ${ }^{153}$ This approach was applied to the $\mathrm{SCF}_{3}$-coupling to (FG)-Ph-OR electrophiles $(\mathrm{FG}=$ functional group, $\mathrm{OR}=$ leaving group in the oxidative addition). First, the tolerance of the leaving group towards the (FG)-Ph- $\mathrm{SCF}_{3}$ product was explored by screening the oxidative addition barriers of the $\mathrm{Ph}-\mathrm{OR}$ bond $\left(\mathrm{OR}=\mathrm{OSO}_{2} \mathrm{CF}_{3}\right.$, $\left.\mathrm{OSO}_{2} \mathrm{Me}, \mathrm{OSO}_{2} \mathrm{Tol}, \mathrm{CO}_{2}{ }^{\mathrm{t}} \mathrm{Bu}, \mathrm{OMe}\right)$, which were compared to that of the $\mathrm{Ph}-\mathrm{SCF}_{3}$ bond $\left(\Delta \mathrm{G}^{\ddagger} \mathrm{OA}\right.$ $=19.2 \mathrm{kcal} \mathrm{mol}^{-1}$ ). In this way, $\mathrm{FG}=\mathrm{OSO}_{2} \mathrm{CF}_{3}$ (i.e. triflate, OTf) was selected due to its lower oxidative addition barrier $\left(\Delta \mathrm{G}^{\ddagger} \mathrm{OA}=14.4 \mathrm{kcal} \mathrm{mol}^{-1}\right)$. Likewise, the compatibility of the OTf group with the functional groups in the (FG)-Ph-OTf electrophile was determined by computing the oxidative addition barrier of the (FG)-Ph bonds. Several functional groups, including $\mathrm{COCF}_{3}, \mathrm{COMe}, \mathrm{CN}, \mathrm{NMe}_{2}$ and $\mathrm{OPh}$, were identified as compatible since they yielded $\Delta \mathrm{G}^{\ddagger} \mathrm{OA}>$ $14.4 \mathrm{kcal} \mathrm{mol}^{-1}$ (Ph-OTf). Catalytic experiments confirmed the tolerance to these leaving and functional groups, which yielded a wide variety of products with high yields between $70-94 \%$. 


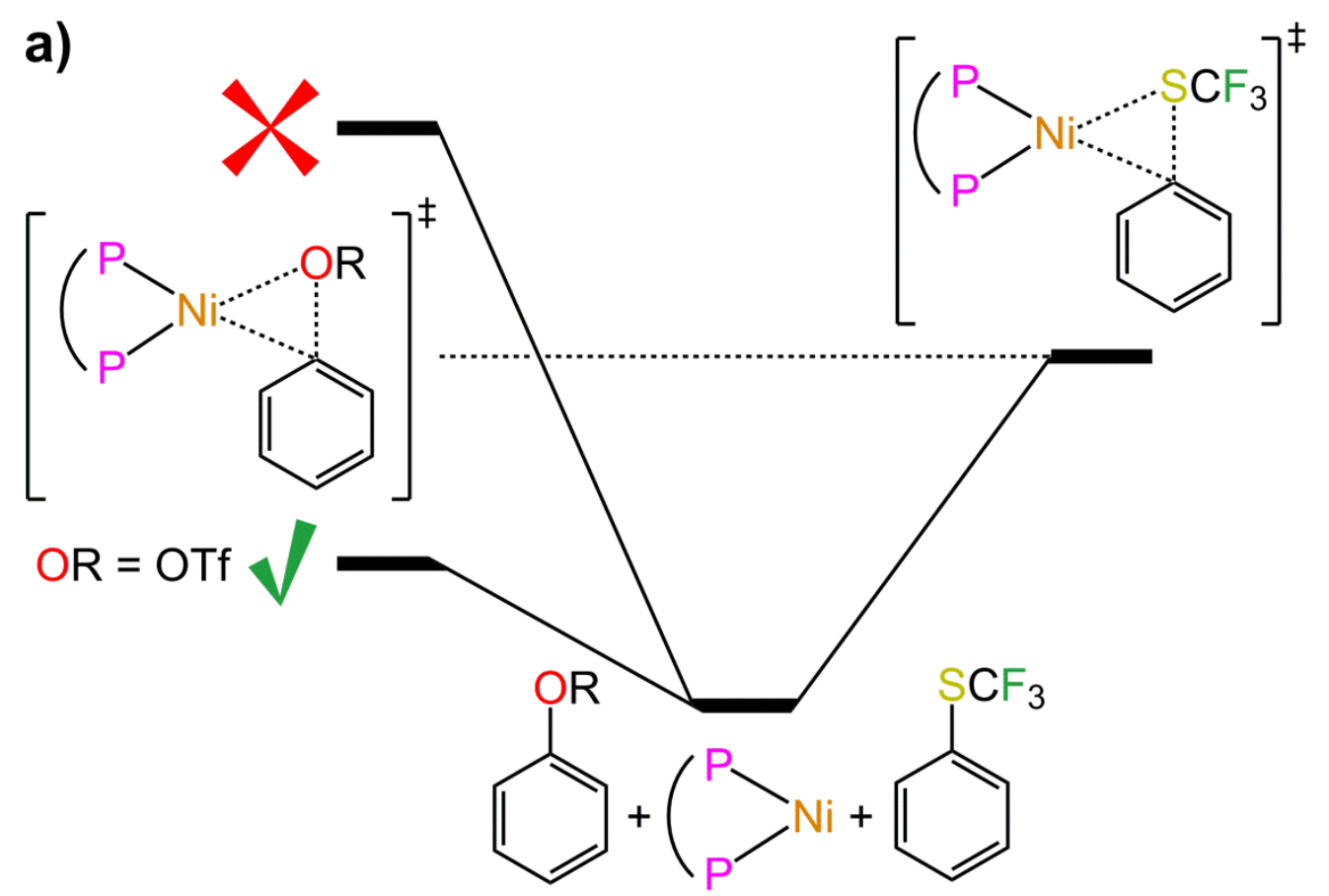

b)

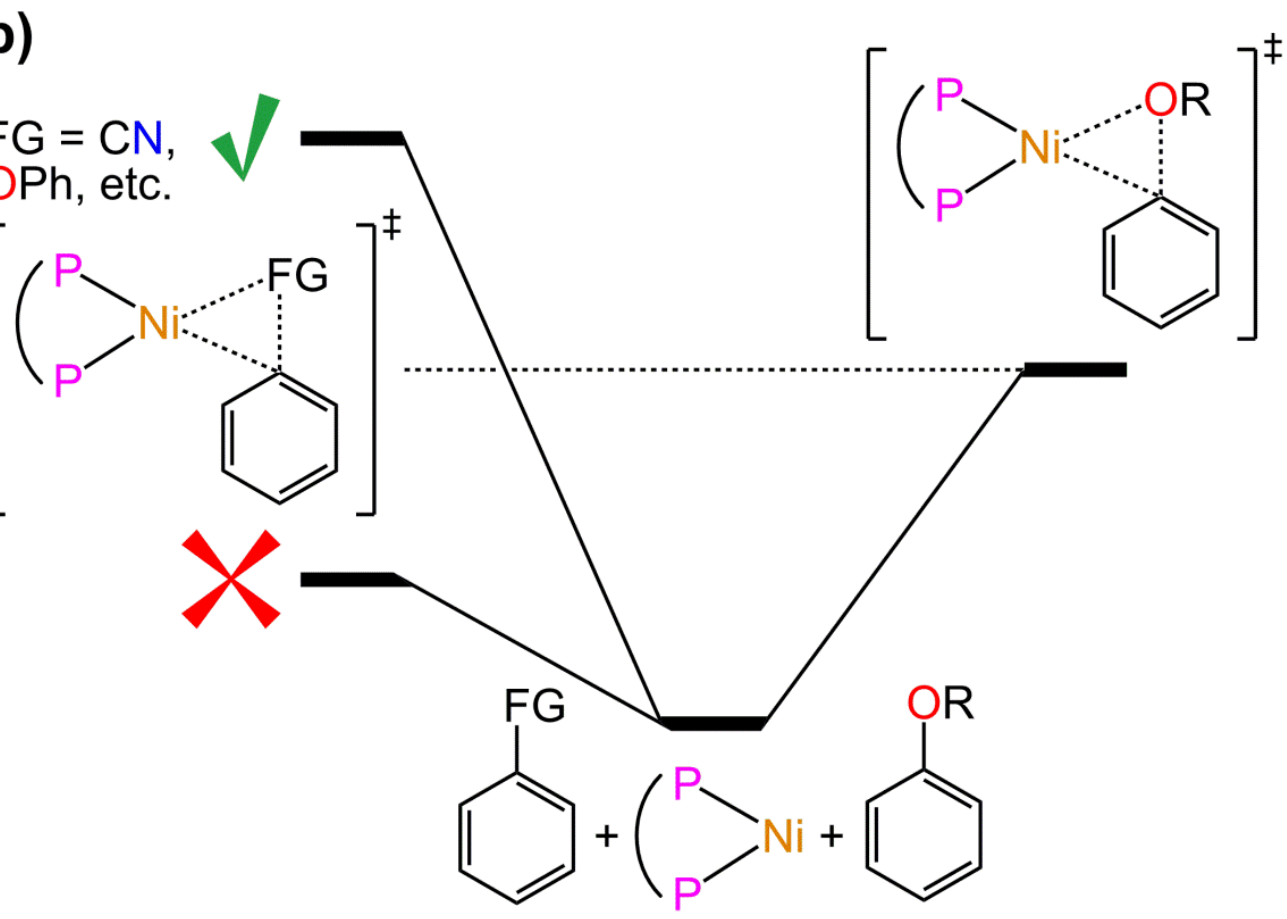

Figure 16. Oxidative addition barrier tolerance of a) the leaving group towards the reaction product and b) the functional group towards the electrophilic reactant (b). 
A possible detrimental off-cycle step is the oxidative addition of the reaction product to the catalyst. Dürr and co-workers explored this process for the coupling of $\left(\mathrm{NMe}_{4}\right) \mathrm{SeCF}_{3}$ to functionalized $\mathrm{Ph}-\mathrm{X}(\mathrm{X}=\mathrm{Br}$ and $\mathrm{I})$, by combining experiments with theory. ${ }^{154}$ The $\mathrm{Ni}(0)$ $\mathrm{Ni}(\operatorname{cod})_{2}$ precatalyst gave poor results, with yields below $10 \%$, due to the oxidative addition of the $\mathrm{Ph}-\mathrm{SeCF}_{3}$ product. $\mathrm{DFT}$ calculations showed that the energy barrier of this reaction $\left(\Delta \mathrm{G}^{\ddagger} \mathrm{OA}=\right.$ $\left.18.0 \mathrm{kcal} \mathrm{mol}^{-1}\right)$ is clearly lower than that involving the electrophilic reactant $\mathrm{Ph}-\mathrm{I}\left(\Delta \mathrm{G}^{\dagger} \mathrm{OA}=24.3\right.$ $\left.\mathrm{kcal} \mathrm{mol}^{-1}\right)$. The overall reaction is also encumbered by poor selectivity due to the formation of side-products, including homocoupled biaryls which suggested the participation of deleterious $\mathrm{Ni}(\mathrm{I})$ species. However, experiments established that a $\mathrm{Ni}(\mathrm{I})$ dimer stabilized by the $\mathrm{NHC} \kappa^{1}-$ SIPr and $\mu$-I ligands (A in Figure 17) is a highly efficient catalyst for this reaction, achieving yields $>90 \%$. The calculations showed that this dimer reverses the preference for the oxidative addition of the $\mathrm{Ph}-\mathrm{SeCF}_{3}$ product over the $\mathrm{Ph}-\mathrm{I}$ reactant from $\Delta \Delta \mathrm{G}^{\star} \mathrm{OA}=6.3$ to $-9.0 \mathrm{kcal} \mathrm{mol}^{-1}$. The oxidative addition reactions to the $\mathrm{Ni}(0)$ monomer and $\mathrm{Ni}(\mathrm{I})$ dimer were fundamentally different, with the latter requiring singlet-to-triplet spin crossover because, whereas the dimer had a singlet ground state, the lowest-energy transition state was found in the triplet state. The authors postulated a reaction mechanism for the dimer in which $\mathrm{Ni}(\mathrm{I})$ stays on-cycle switching back and forth to the $\mathrm{Ni}(\mathrm{II})$ oxidation state. The $\mathrm{SeCF}_{3}{ }^{-}$nucleophile and $\mathrm{Ph}^{+}$electrophile are installed as bridging and terminal ligands, by transmetallation and oxidative addition, respectively, prior to the reductive elimination of the $\mathrm{Ph}-\mathrm{SeCF}_{3}$ product. In this way, the catalytic cycle excludes the formation of monomeric nickel(0,I,II) species opening undesired pathways. Further, the formation of a bimetallic $\mathrm{Ni}(\mathrm{I})_{2}$ core is more favorable than that of a pair of $\mathrm{Ni}(\mathrm{III})$ monomers. The efficiency of $\mathrm{Ni}(\mathrm{I})$ dinuclear catalysts was also demonstrated by Matsubara and co-workers for the Kumada-Tamao-Corriu cross-coupling reaction. ${ }^{111}$ In this 
case, the bimetallic core is stabilized by either one or two $p$-tolyl bridging ligands ( $\mathbf{B}$ and $\mathbf{C}$ in Figure 17). DFT calculations showed the ability of the $\mu$ - $p$-tolyl ligand in $\mathbf{B}$ to slip into a $\kappa^{1}$ terminal position, allowing for the oxidative addition of the electrophile across the $\mathrm{Ni}-\mathrm{Ni}$ bridge.
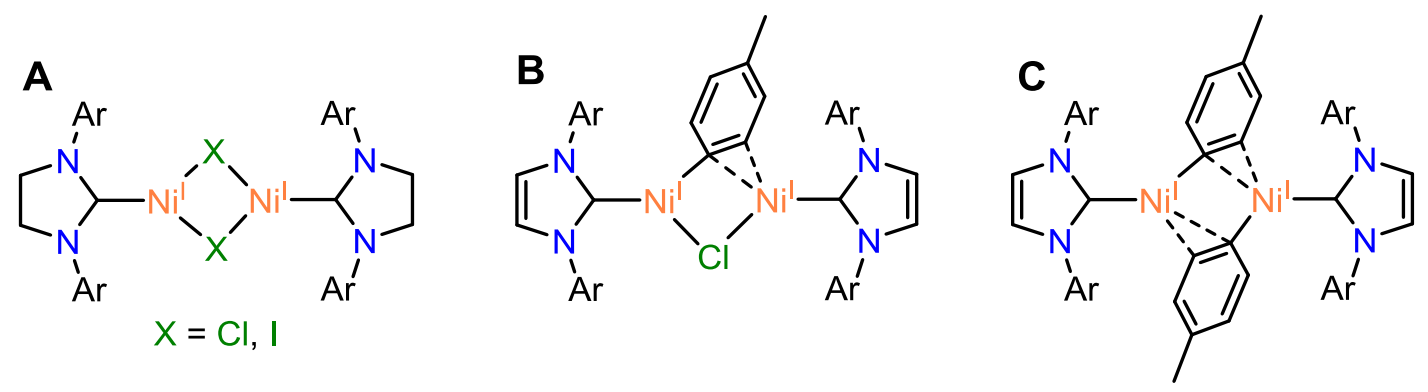

Figure 17. $\mathrm{Ni}(\mathrm{I})$ dimers involved in catalytic cross-coupling reactions.

Nickel complexes based on monodentate phosphine ligands can also generate dinuclear precursors to $\mathrm{Ni}(\mathrm{I})$ species. Manzoor and co-workers combined kinetic experiments with DFT calculations in the study of $\mathrm{Ni}\left(\mathrm{PPh}_{3}\right)_{4}$ and $\mathrm{Ni}\left(\mathrm{PPh}_{3}\right)_{3}(\mathrm{X})\left(\mathrm{X}=\mathrm{Cl}, \mathrm{Br}\right.$ and I) precatalysts. ${ }^{155}$ Whereas the $\operatorname{Ni}(0)$ precatalyst showed good performance for the Suzuki-Miyaura and HeckMizorki couplings, the Ni(I) precatalyst was only active in the former, showing the influence of the reaction conditions and the nature of the substrate. The product of the oxidative addition of $\mathrm{PhCl}$ to $\mathrm{Ni}\left(\mathrm{PPh}_{3}\right)_{4}$ was identified as trans- $(\mathrm{Ph})(\mathrm{Cl}) \mathrm{Ni}\left(\mathrm{PPh}_{3}\right)_{2}$, which, over time, yielded biphenyl and a $\mathrm{Ni}(\mathrm{I})$ complex in a slowly-increasing concentration. EPR and NMR spectroscopy enabled the identification of this species as $\mathrm{Ni}\left(\mathrm{PPh}_{3}\right)_{2}(\mathrm{Cl})$. Mechanistic studies suggested that the formation of this complex involved the aggregation of two trans- $(\mathrm{Ph})(\mathrm{Cl}) \mathrm{Ni}\left(\mathrm{PPh}_{3}\right)_{2}$ complexes by the decoordination of one $\mathrm{PPh}_{3}$ ligand, which was accompanied by the formation of a dative $\mathrm{Ni}-\mathrm{Cl} \rightarrow \mathrm{Ni}$ bridging bond. In contrast, a DFT study by Funes-Ardoiz and co-workers showed that the reaction mechanism may involve only mononuclear intermediates. ${ }^{156}$ After decoordination of a phosphine ligand, the resulting tricoordinated $\mathrm{Ni}(0) \mathrm{Ni}\left(\mathrm{PR}_{3}\right)_{3}$ complex generated a $\mathrm{Ni}(\mathrm{I})$ species by radical abstraction of the halide from the $\mathrm{Ar}-\mathrm{X}$ reactant. This 
reaction involved an unusual open-shell singlet transition state and competed with oxidative addition yielding Ni(II) intermediates. The kinetic balance between these two mechanisms was strongly dependent on the nature of the halide $(\mathrm{Cl}, \mathrm{Br}$ or $\mathrm{I})$ and the ligand (aryl or alkyl substituents in the monodentate $\mathrm{PR}_{3}$ ).

Before closing this section, it is worth noting that mononuclear Ni(I) complexes have also been postulated as on-cycle active species ${ }^{157,158}$ yielding the desired reaction products. E.g., in an experimental/computational study, Lavoie and co-workers ${ }^{159}$ showed that a $\mathrm{Ni}(\mathrm{I}) / \mathrm{Ni}(\mathrm{III})$ catalytic cycle $^{160,161,162,163,164,165,166,167}$ can compete with the $\mathrm{Ni}(0) / \mathrm{Ni}(\mathrm{II}) .{ }^{168,169}$ These two mechanisms differed in the nature of the rate-determining step, which was either the oxidative addition $(\mathrm{Ni}(\mathrm{I}) / \mathrm{Ni}(\mathrm{III}))$ or the reductive elimination $(\mathrm{Ni}(0) / \mathrm{Ni}(\mathrm{II}))$. The preference for one of these two mechanisms was seemingly decided by a complex interplay between the nature of the nucleophile, precatalyst and ancillary ligand. Only specific combinations of these three ingredients yielded $\mathrm{Ni}(\mathrm{I})$ catalysts superior to their $\mathrm{Ni}(\mathrm{II})$ counterparts.

\section{CONCLUSIONS AND OUTLOOK}

The works selected in this Perspective show that state-of-the-art experimental and computational methods can be used and combined to determine the off-cycle part of the reaction mechanisms underlying metal-catalyzed cross-coupling reactions. Several off-cycle activation reactions have been characterized, including ligand-to-ligand H-shift, nucleophilic attack of the base and dimer disproportionation. Off-cycle deactivation reactions include monomer comproportionation, singlet-to-triplet spin crossover, decomposition of unstable metal-aryl species, radical halide abstraction, $\beta$-F elimination, retro-transmetallation and undesired oxidative additions. This rich variety of reactions shows that off-cycle pathways in cross-couplings can originate not only from 
the active species connected to the precatalyst, but also from other on-cycle intermediates. Further, whereas some of these reactions are seemingly rather specific (e.g. the decomposition of $\mathrm{Ni}(\mathrm{I})$-aryl intermediates), others appear to be ubiquitous (e.g. dimerization), though they may involve different mechanisms in each case. These reactions also illustrate the fundamental differences between palladium and nickel catalysts. Notably, whereas $\operatorname{Pd}(\mathrm{I})$ is mostly relevant in bimetallic complexes, Ni(I) can yield a wide variety of species with different nuclearity and supporting ligands, which can be either on- or off-cycle and have either productive or detrimental effects.

The understanding of the off-cycle mechanisms allows for new catalyst design approaches aimed at promoting activation meanwhile preventing deactivation. These strategies include the stereoelectronic fine-tuning of the ligands to prevent dimerization, the formulation of easily activated dimers and the appropriate choice of reaction conditions (e.g. solvent and base used) and substrates (e.g. compatibility between leaving and functional groups). In this wider mechanistic framework, precatalyst design principles can be formulated in a new modular manner, in which one ancillary ligand (or a part of it) is optimized for the on-cycle part of the mechanism, whereas another is optimized for the off-cycle. A paradigmatic example of this approach is the NHC-Pd-allyl catalytic platform, in which the NHC ligand can be adjusted to promote the transformation of reactants into products, whereas the allyl can be adjusted to accelerate the activation of the precatalyst and to exclude its deactivation by dimerization.

Frontier research in the field of metal-catalyzed cross-couplings remains driven by the need to couple a wider range of substrates with low catalyst loading at mild conditions. Since these three features are strongly connected to both on- and off-cycle reactions, design strategies considering these two dimensions of the mechanism shall make a major contribution to the development of 
better catalysts. The case of nickel is especially appealing; though more cheap and environmentfriendly than palladium, easy access to multiple $\mathrm{Ni}(\mathrm{I})$ species does often undermine catalysis. A deeper understanding of the nickel off-cycle chemistry, including the interplay between the nature of the ligand and the stability of the possible oxidation states, can expand the application range of this metal. This goal is challenged by the experimental difficulties in the isolation and characterization of these species. From a computational perspective, nickel complexes are prone to have multiple electronic states within a narrow range of energies. This prompts the use of accurate quantum mechanics methods, which, ideally, would combine static and dynamic correlation. The use of these accurate methods is encumbered by the high cost of the calculations on large systems based on bimetallic cores supported by bulky ligands. Another issue that should be tackled is the comprehensive exploration of the potential energy surface underlying the offcycle chemistry. In this regard, the novel algorithms for the automated search of reaction pathways show high promise. ${ }^{170,171,172}$

In summary, the exploration of the off-cycle reactions in cross-coupling reactions has enabled new precatalyst design strategies. These strategies have already contributed to the optimization of existing catalytic systems based on palladium and can play a major role in the development of highly active and robust nickel precatalysts. 


\section{AUTHOR INFORMATION}

\section{Corresponding Authors}

*E-Mail: david.balcells@kjemi.uio.no

*E-Mail: ainara.nova@kjemi.uio.no

\section{ORCID}

David Balcells: 0000-0002-3389-0543

Ainara Nova: 0000-0003-3368-7702

\section{Notes}

The authors declare no competing financial interest.

\section{ACKNOWLEDGEMENTS}

D.B. and A.N. acknowledge the support from the Research Council of Norway through its Centers of Excellence scheme, including the CTCC (Centre for Theoretical and Computational Chemistry, project number 179568) and the Hylleraas Centre for Quantum Molecular Sciences (project number 262695), and the Norwegian Metacenter for Computational Science (NOTUR, project nn4654k). D.B. also thanks the EU REA for a Marie Curie Fellowship (project CompuWOC/618303). A.N. also thanks the support from the Research Council of Norway through its FRINATEK scheme (project numbers 221801 and 250044). The authors thank Prof. Nilay Hazari for helpful insights and discussions. 


\section{REFERENCES}

${ }^{1}$ Hartwig, J. F. Acc. Chem. Res., 2008, 41, 1534.

${ }^{2}$ Marion, N.; Nolan, S. P. Acc. Chem. Res., 2008, 41, 1440.

${ }^{3} \mathrm{Fu}, \mathrm{G}$. C. Acc. Chem. Res., 2008, 41, 1555.

${ }^{4}$ Würtz, S.; Glorius, F. Acc. Chem. Res., 2008, 41, 1523.

${ }^{5}$ Martin, R.; Buchwald, S. L. Acc. Chem. Res. 2008, 41, 1461.

${ }^{6}$ Valente, C.; Calimsiz, S.; Hoi, K. H.; Mallik, D.; Sayah, M.; Organ, M. G. Angew. Chem. Int. Ed., $2012,51,3314$.

${ }^{7}$ New Trends in Cross-Coupling: Theory and Applications. RSC Catalysis Series No. 21; Colacot, T. J, Ed.; The Royal Society of Chemistry: Cambridge, U.K., 2015; pp 1-864.

${ }^{8}$ Gildner, P. G.; Colacot, T. J. Organometallics, 2015, 34, 5497.

${ }^{9}$ Hazari, N.; Melvin, P. R.; Beromi, M. M. Nature Rev. Chem., 2017, 1, 0025.

${ }^{10}$ Li, H.; Seechurn, C. C. C. J.; Colacot, T. J. ACS Catalysis, 2012, 2, 1147.

${ }^{11}$ Giannerini, M.; Fañanás-Mastral, M.; Feringa, B. L. Nat. Chem., 2013, 5, 667.

${ }^{12}$ Stuart, D. R.; Fagnou, K. Science, 2007, 316, 1172.

${ }^{13}$ Choi, J.; Fu, G. C. Science, 2017, 356, DOI: 10.1126/science.aaf7230.

14 Tellis, J. C.; Primer, D. N.; Molander, G. A. Science, 2014, 345, 433.

${ }^{15}$ Espinet, P.; Echavarren, A. M. Angew. Chem. Int. Ed., 2004, 43, 4704.

${ }^{16}$ Littke, A. F.; Fu, G. C. Angew. Chem. Int. Ed., 2002, 41, 4176.

${ }^{17}$ Seechurn, C. C. C. J.; Kitching, M. O.; Colacot, T. J.; Snieckus, V. Angew. Chem. Int. Ed., 2012, $51,5062$.

${ }^{18}$ Wu, X.-F.; Anbarasan, P.; Neumann, H.; Beller, M. Angew. Chem. Int. Ed., 2010, 49, 9047.

${ }^{19}$ Miyaura, N.; Suzuki, A. Chem. Rev., 1995, 95, 2457.

${ }^{20}$ Miyaura, N.; Yamada, K.; Suzuki, A. Tetrahedron Lett., 1979, 20, 3437.

${ }^{21}$ Littke, A. F.; Dai, C.; Fu, G. C. J. Am. Chem. Soc., 2000, 122, 4020.

${ }^{22}$ Kataoka, N.; Shelby, Q.; Stambuli, J. P.; Hartwig, J. F. J. Org. Chem., 2002, 67, 5553.

${ }^{23}$ Colacot, T. J.; Shea, H. A. Org. Lett., 2004, 6, 3731.

${ }^{24}$ Marion, N.; Navarro, O.; Mei, J.; Stevens, E. D.; Scott, N. M.; Nolan, S. P. J. Am. Chem. Soc., 2006, $128,4101$. 
${ }^{25}$ O’Brien, C. J.; Kantchev, E. A. B.; Valente, C.; Hadei, N.; Chass, G. A.; Lough, A.; Hopkinson, A. C.; Organ, M. G. Chem. Eur. J., 2006, 12, 4743.

${ }^{26}$ Barder, T. E.; Walker, S. D.; Martinelli, J. R.; Buchwald, S. L. J. Am. Chem. Soc., 2005, 127, 4685.

${ }^{27}$ Kinzel, T.; Zhang, Y.; Buchwald, S. L. J. Am. Chem. Soc., 2010, 132, 14073.

${ }^{28}$ Melvin, P. R.; Nova, A.; Balcells, D.; Dai, W.; Hazari, N.; Hruszkewycz, D. P.; Shah, H. P.; Tudge, M. T. ACS Catal., 2015, 5, 3680 .

${ }^{29}$ Beletskaya, I. P.; Cheprakov, A. V. Chem. Rev., 2000, 100, 3009.

${ }^{30}$ Dai, C. Y.; Fu, G. C. J. Am. Chem. Soc., 2001, 123, 2719.

${ }^{31}$ Christmann, U.; Vilar, R. Angew. Chem. Int. Ed., 2005, 44, 366.

${ }^{32}$ Braga, A. A. C.; Ujaque, G.; Maseras, F. Organometallics, 2006, 25, 3647.

${ }^{33}$ Braga, A. A. C.; Morgon, N. H.; Ujaque, G.; Maseras, F. J. Am. Chem. Soc., 2005, 127, 9298.

${ }^{34}$ Garcia-Melchor, M.; Braga, A. A. C.; Lledos, A.; Ujaque, G.; Maseras, F. Acc. Chem. Res., 2013, $46,2626$.

35 Amatore, C.; Jutand, A.; Acc. Chem. Res., 2000, 33, 314.

${ }^{36}$ Amatore, C.; Jutand, A. J. Organomet. Chem., 1999, 576, 254.

${ }^{37}$ Weng, Z. Q.; Teo, S. H.; Hor, T. S. A. Acc. Chem. Res., 2007, 40, 676.

${ }^{38}$ Ahlquist, M.; Fristrup, P.; Tanner, D.; Norrby, P. O. Organometallics, 2006, 25, 2066.

${ }^{39}$ MorenoManas, M.; Perez, M.; Pleixats, R. J. Org. Chem., 1996, 61, 2346.

${ }^{40}$ Smith, G. B.; Dezeny, G. C.; Hughes, D. L.; King, A. O.; Verhoeven, T. R.; J. Org. Chem., 1994, $59,8151$.

${ }^{41}$ Netherton, M. R.; Fu, G. C. Angew. Chem. Int. Ed., 2002, 41, 3910.

${ }^{42}$ Sumimoto, M.; Iwane, N.; Takahama, T.; Sakaki, S. J. Am. Chem. Soc., 2004, 126, 10457.

${ }^{43}$ Meir, R.; Kozuch, S.; Uhe, A.; Shaik, S. Chem. Eur. J., 2011, 17, 7623.

${ }^{44}$ Kozuch, S.; Amatore, C.; Jutand, A.; Shaik, S. Organometallics, 2005, 24, 2319.

${ }^{45}$ Powers, I. G.; Uyeda, C. ACS Catal., 2017, 7, 936.

${ }^{46}$ Hazari, N.; Hruszkewycz, D. P. Chem. Soc. Rev., 2016, 45, 2871.

${ }^{47}$ Jaworski, J. N.; McCann, S. D.; Guzei, I. A.; Stahl, S. S. Angew. Chem. Int. Ed., 2017, 56, 3605.

${ }^{48}$ Oldenhof, S.; Lutz, M.; de Bruin, B., van der Vlugt, J. I.; Reek, J. N. H. Organometallics, 2014, $33,7293$. 
${ }^{49}$ Barnett, B. R.; Labios, L. A.; Stauber, J. M.; Moore, C. E.; Rheingold, A. L.; Figueroa, J. S. Organometallics 2017, 36, 944.

${ }^{50}$ Campos, J.; Nova, A.; Kolychev, E. L.; Aldridge, S. Chem. Eur. J., 2017, 23, 12655.

${ }^{51}$ Kashin, A. S.; Ananikov, V. P. J. Org. Chem., 2013, 78, 11117.

${ }^{52}$ Iwasawa, T.; Tokunaga, M.; Obora, Y.; Tsuji, Y. J. Am. Chem. Soc., 2004, 126, 6554.

${ }^{53}$ Ackerman, L. K. G.; Lovell, M. M.; Weix, D. J. Nature, 2015, 524, 454.

${ }^{54}$ Hruszkewycz, D. P.; Guard, L. M.; Balcells, D.; Feldman, N.; Hazari, N.; Tilset, M. Organometallics, 2015, 34, 381.

${ }^{55}$ van Leeuwen, P. W. N. M. Appl. Catal. Gen., 2001, 212, 61.

${ }^{56}$ Kozuch, S.; Shaik, S. J. Am. Chem. Soc., 2006, 128, 3355.

${ }^{57}$ Kozuch, S.; Shaik, S. Acc. Chem. Res., 2011, 44, 101.

${ }^{58}$ Rush, E.; Pringle, P. G.; Harvey, J. N. Angew. Chem. Int. Ed., 2014, 53, 8672.

59 Jover, J. Phys. Chem. Chem. Phys., 2017, 19, 29344.

${ }^{60}$ Kalek, M.; Himo, F. J. Am. Chem. Soc., 2017, 139, 10250.

${ }^{61}$ Beromi, M. M.; Nova, A.; Balcells, D.; Brasacchio, A. M.; Brudvig, G. W.; Guard, L. M.; Hazari, N.; Vinyard, D. J. J. Am. Chem. Soc., 2017, 139, 922.

${ }^{62}$ Zhou, J.; Berthel, J. H. J.; Kuntze-Fechner, M. W.; Friedrich, A.; Marder, T. B.; Radius, U. J. Org. Chem., 2016, $81,5789$.

${ }^{63}$ Neely, J. M.; Bezdek, M. J.; Chirik, P. J. ACS Cent. Sci., 2016, 2, 935.

${ }^{64}$ Asghar, S.; Tailor, S. B.; Elorriaga, D.; Bedford, R. B. Angew. Chem. Int. Ed., 2017, 56, 16367.

${ }^{65} \mathrm{Su}$, B.; Cao, Z. C.; Shi, Z. J. Acc. Chem. Res., 2015, 48, 886.

${ }^{66}$ Liu, C.; Liu, D.; Lei, A. W. Acc. Chem. Res., 2014, 47, 3459.

${ }^{67}$ Dudnik, A. S.; Fu, G. C. J. Am. Chem. Soc., 2012, 134, 10693.

${ }^{68}$ Crabtree, R. H. Chem. Rev., 2015, 115, 9532.

${ }^{69}$ Sperger, T.; Sanhueza, I. A.; Kalvet, I.; Schoenebeck, F. Chem. Rev., 2015, 115, 9532.

${ }^{70}$ Sperger, T.; Sanhueza, I. A.; Schoenebeck, F. Acc. Chem. Res., 2016, 49, 1311.

${ }^{71}$ Bonney, K. J.; Schoenebeck, F. Chem. Soc. Rev., 2014, 43, 6609. 
${ }^{72}$ Foley, N. A.; Lee, J. P.; Ke, Z. F.; Gunnoe, T. B.; Cundari, T. R. Acc. Chem. Res., 2009, $42,585$.

${ }^{73}$ Cheong, P. H. Y.; Legault, C. Y.; Um, J. M.; Celebi-Olcum, N.; Houk, K. N. Chem. Rev., 2011, $111,5042$.

${ }^{74}$ Ziegler, T.; Autschbach, J. Chem. Rev., 2005, 105, 2695.

${ }^{75}$ Cramer, C. J.; Tolman, W. B. Acc. Chem. Res., 2007, 40, 601.

${ }^{76}$ Balcells, D.; Clot, E.; Eisenstein, O. Chem. Rev., 2010, 110, 749.

${ }^{77}$ Hintermair, U.; Sheehan, S. W.; Parent, A. R.; Ess, D. H.; Richens, D. T.; Vaccaro, P. H.; Brudvig, G. W.; Crabtree, R. H. J. Am. Chem. Soc., 2013, 135, 10837.

${ }^{78}$ Minenkov, Y.; Singstad, A.; Occhipinti, G.; Jensen, V. R. Dalton Trans., 2012, 41, 5526.

${ }^{79}$ Zhao, Y.; Truhlar, D. G. Theor. Chem. Acc., 2008, 120, 215.

${ }^{80}$ Zhao, Y.; Truhlar, D. G. Acc. Chem. Res., 2008, 41, 157.

${ }^{81}$ Tao, J. M.; Perdew, J. P.; Staroverov, V. N.; Scuseria, G. E. Phys. Rev. Lett., 2003, 91, 146401.

${ }^{82}$ Grimme, S. J. Comput. Chem., 2004, 25, 1463.

${ }^{83}$ Grimme, S.; Antony, J.; Ehrlich, S.; Krieg, H. J. Chem. Phys., 2010, 132, 154104.

${ }^{84}$ Cramer, C. J.; Truhlar, D. G. Acc. Chem. Res., 2008, 41, 760.

${ }^{85}$ Marenich, A. V.; Cramer, C. J.; Truhlar, D. G. J. Phys. Chem. B, 2009, 113, 6378.

${ }^{86}$ Cramer, C. J.; Truhlar, D. G. Chem. Rev., 1999, 99, 2161.

${ }^{87}$ Tomasi, J.; Mennucci, B.; Cammi, R. Chem. Rev., 2005, 105, 2999.

${ }^{88}$ Miertus, S.; Scrocco, E.; Tomasi, J. Chem. Phys., 1981, 55, 117.

${ }^{89}$ Viciu, M. S.; Germaneau, R. F.; Navarro-Fernandez, O.; Stevens, E. D.; Nolan, S. P. Organometallics, 2002, 21, 5470.

${ }^{90}$ Borjian, S.; Baird, M. C. Organometallics, 2014, 33, 3936.

${ }^{91}$ Ortiz, D.; Blug, M.; Le Goff, X.-F.; Le Floch, P.; Mezailles, N.; Maître, P. Organometallics, 2012, $31,5975$.

${ }^{92}$ Melvin, P. R.; Balcells, D.; Hazari, N.; Nova, A.; ACS Catal., 2015, 5, 5596.

${ }^{93}$ Li, H.; Grasa, G. A.; Colacot, T. J. Org. Lett., 2010, 12, 3332.

${ }^{94}$ Fantasia, S.; Nolan, S. P. Chem. Eur. J., 2008, 14, 6987.

95 Trost, B. M.; Ryan, M. C. Angew. Chem. Int. Ed., 2017, 56, 2862. 
96 Viciu, M. S.; Navarro, O.; Germaneau, R. F.; Kelly, R. A.; Sommer, W.; Marion, N.; Stevens, E. D.; Cavallo, L.; Nolan, S. P. Organometallics, 2004, 23, 1629.

${ }^{97}$ Meconi, G. M.; Vummaleti, S. V.; Luque-Urrutia, J. A.; Belanzoni, P.; Nolan, S. P.; Jacobsen, H.; Cavallo, L.; Solà, M.; Poater, A. Organometallics, 2017, 36, 2088.

${ }^{98}$ Seechurn, C. C. C. J.; Parisel, S. L.; Colacot, T. J. J. Org. Chem., 2011, 76, 7918.

${ }^{99}$ Stambuli, J. P.; Kuwano, R.; Hartwig, J. F. Angew. Chem. Int. Ed., 2002, 41, 4746.

${ }^{100}$ Hama, T.; Liu, X.; Culkin, D. A.; Hartwig, J. F. J. Am. Chem. Soc., 2003, 125, 11176.

${ }^{101}$ Yin, G.; Kalvet, I.; Schoenebeck, F. Angew. Chem. Int. Ed., 2015, 54, 6809.

${ }^{102}$ Aufiero, M.; Sperger, T.; Tsang, A. S.-K.; Schoenebeck, F. Angew. Chem. Int. Ed., 2015, 54, 10322.

${ }^{103}$ Proutiere, F.; Aufiero, M.; Schoenebeck, F. J. Am. Chem. Soc., 2012, 134, 606.

${ }^{104}$ Proutiere, F.; Schoenebeck, F. Angew. Chem. Int. Ed., 2011, 50, 8192.

105 Aufiero, M.; Scattolin, T.; Proutière, F. Schoenebeck, F. Organometallics, 2015, 34, 5191.

${ }^{106}$ Mayr, H.; Ofial, A. R. J. Phys. Org. Chem., 2008, 21, 584.

${ }^{107}$ Kalvet, I.; Magnin, G.; Schoenebeck, F. Angew. Chem. Int. Ed., 2017, 56, 1581.

${ }^{108}$ Kalvet, I.; Sperger, T.; Scattolin, T.; Magnin, G.; Schoenebeck, F. Angew. Chem. Int. Ed., 2017, 56, 7078.

${ }^{109}$ Bonney, K. J.; Proutiere, F.; Schoenebeck, F. Chem. Sci., 2013, 4, 4434.

${ }^{110}$ Kalvet, I.; Bonney, K. J.; Schoenebeck, F. J. Org. Chem., 2014, 79, 12041.

111 Matsubara, K.; Yamamoto, H.; Miyazaki, S.; Inatomi, T.; Nonaka, K.; Koga, Y.; Yamada, Y.; Veiros, L. F.; Kirchner, K. Organometallics, 2017, 36, 255.

112 Weissman, H.; Shimon, L. J. W.; Milstein, D. Organometallics, 2004, 23, 3931.

${ }^{113}$ Barder, T. E. J. Am. Chem. Soc., 2006, 128, 898.

${ }^{114}$ Finke, A. D.; Elleby, E. C.; Boyd, M. J.; Weissman, H.; Moore, J. S. J. Org. Chem., 2009, 74, 8897.

${ }^{115}$ Denmark, S. E.; Baird, J. D.; Regens, C. S. J. Org. Chem., 2008, 73, 1440.

116 Jimeno, C.; Christmann, U.; Escudero-Adan, E. C.; Vilar, R.; Pericas, M. A. Chem. Eur. J., 2012, $18,16510$.

117 Werner, H. Adv. Organomet. Chem., 1981, 19, 155.

${ }^{118}$ Murahashi, T.; Kurosawa, H. Coord. Chem. Rev. , 2002, 231, 207.

${ }^{119}$ Hazari, N.; Hruszkewycz, D. P.; Wu, J. Synlett 2011, 1793. 
${ }^{120}$ Hruszkewycz, D. P.; Balcells, D.; Guard, L. M.; Hazari, N.; Tilset, M. J. Am. Chem. Soc., 2014, $136,7300$.

${ }^{121}$ Lei, P.; Meng, G.; Shi, S.; Ling, Y.; An, J.; Szostak, R.; Szostak, M. Chem. Sci., 2017, 8, 6525.

${ }^{122}$ DeAngelis, A. J. ; Gildner, P. G.; Chow, R.; Colacot, T. J. J. Org. Chem., 2015, 80, 6794.

${ }^{123}$ Proutiere, F.; Lyngvi, E.; Aufiero, M.; Sanhueza, I. A.; Schoenebeck, F. Organometallics, 2014, $33,6879$.

${ }^{124}$ Chartoire, A.; Lesieur, M.; Falivene, L.; Slawin, A. M. Z.; Cavallo, L.; Cazin, C. S. J.; Nolan, S. P. Chem. Eur. $J ., 2012,18,4517$.

125 Barnett, B. R.; Labios, L. A.; Stauber, J. M.; Moore, C. E.; Rheingold, A. L.; Figueroa, J. S. Organometallics, $\mathbf{2 0 1 7}, 36,944$.

${ }^{126}$ Campos, J.; Nova, A.; Kolychev, E. L.; Aldridge, S. Chem. Eur. J., 2017, 23, 12655.

127 Seechurn, C. C. C. J.; Sperger, T.; Scrase, T. G.; Schoenebeck, F.; Colacot, T. J. J. Am. Chem. Soc., 2017, 139, 5194.

${ }^{128}$ Liu, X.; Hsiao, C.-C.; Kalvet, I.; Leiendecker, M.; Guo, L.; Schoenebeck, F.; Rueping, M. Angew. Chem. Int. Ed., 2016, 55, 6093 .

${ }^{129}$ Malineni, J.; Jezorek, R. L.; Zhang, N.; Percec, V. Synthesis, 2016, 48, 2795.

${ }^{130}$ Magano, J.; Monfette, S. ACS Catal., 2015, 5, 3120.

${ }^{131}$ Shields, J. D.; Gray, E. E.; Doyle, A. G. Org. Lett., 2015, 17, 2166.

132 Ananikov, V. P. ACS Catal., 2015, 5, 1964.

133 Tasker, S. Z.; Standley, E. A.; Jamison, T. F. Nature, 2014, 509, 299.

${ }^{134} \mathrm{Hu}$, X. Chem. Sci., 2011, 2, 1867.

135 Rosen, B. M.; Quasdorf, K. W.; Wilson, D. A.; Zhang, N.; Resmerita, A.-M.; Garg, N. K.; Percec, V. Chem. Rev., 2011, 111, 1346.

${ }^{136}$ Quasdorf, K. W.; Riener, M.; Petrova, K. V.; Garg, N. K. J. Am. Chem. Soc., 2009, 131, 17748.

${ }^{137}$ Jezorek, R. L.; Zhang, N.; Leowanawat, P.; Bunner, M. H.; Gutsche, N.; Pesti, A. K. R.; Olsen, J. T.; Percec, V. Org. Lett., 2014, 16, 6326.

${ }^{138}$ Ke, H.; Chen, X.; Zou, G. J. Org. Chem., 2014, 79, 7132.

139 Snieckus, V. Chem. Rev., 1990, 90, 879.

${ }^{140}$ Board, J.; Cosman, J. L.; Rantanen, T.; Singh, S. P.; Snieckus, V. Platinum Met. Rev., 2013, $57,234$. 
${ }^{141}$ Antoft-Finch, A.; Blackburn, T.; Snieckus, V. J. Am. Chem. Soc., 2009, 131, 17750.

${ }^{142}$ Guard, L. M.; Beromi, M. M.; Brudvig, G. W.; Hazari, N.; Vinyard, D. J. Angew. Chem. Int. Ed., 2015, 54, 13352 .

${ }^{143}$ Lin, C. Y.; Power, P. P. Chem. Soc. Rev., 2017, 46, 5347.

${ }^{144}$ Yin, G.; Kalvet, I.; Englert, U.; Schoenebeck, F. J. Am. Chem. Soc., 2015, 137, 4164.

${ }^{145}$ Christmann, U.; Pantazis, D. A.; Benet-Buchholz, J.; McGrady, J. E.; Maseras, F.; Vilar, R. J. Am. Chem. Soc., 2006, $128,6376$.

${ }^{146}$ Christmann, U.; Pantazis, D. A.; Benet-Buchholz, J.; McGrady, J. E.; Maseras, F.; Vilar, R. Organometallics, 2006, 25, 5990 .

${ }^{147}$ Kalvet, I.; Guo, Q.; Tizzard, G. J.; Schoenebeck, F. ACS Catal., 2017, 7, 2126.

${ }^{148}$ Bajo, S.; Laidlaw, G.; Kennedy, A. R.; Sproules, S.; Nelson, D. J. Organometallics, 2017, 36, 1662.

${ }^{149}$ Wang, J.; Meng, G.; Xie, K.; Li, L.; Sun, H.; Huang, Z. ACS Catal., 2017, 7, 7421.

${ }^{150}$ Pérez-Temprano, M. H.; Nova, A.; Casares, J. A.; Espinet, P. J. Am. Chem. Soc., 2008, 130, 10518.

${ }^{151}$ Liu, Q.; Lan, Y.; Liu, J.; Li, G.; Wu, Y.-D.; Lei, A. J. Am. Chem. Soc., 2009, 131, 10201.

152 del Pozo, J.; Salas, G.; Álvarez, R.; Casares, J. A.; Espinet, P. Organometallics, 2016, 35, 3604.

${ }^{153}$ Dürr, A. B.; Yin, G.; Kalvet, I.; Napoly, F.; Schoenebeck, F. Chem. Sci., 2016, 7, 1076.

154 Dürr, A. B.; Fisher, H. C.; Kalvet, I.; Truong, K.-N.; Schoenebeck, F. Angew. Chem. Int. Ed., 2017, 56, 13431.

${ }^{155}$ Manzoor, A.; Wienefeld, P.; Baird, M. C.; Budzelaar, P. H. M. Organometallics, 2017, $36,3508$.

${ }^{156}$ Funes-Ardoiz, I.; Nelson, D. J.; Maseras, F. Chem. Eur. J., 2017, 23, 16728.

${ }^{157}$ Anderson, T. J.; Jones, G. D.; Vicic, D. A. J. Am. Chem. Soc., 2004, 126, 8100.

${ }^{158}$ Cornella, J.; Gómez-Bengoa, E.; Martin, R. J. Am. Chem. Soc., 2013, 135, 1997.

${ }^{159}$ Lavoie, C. M.; McDonald, R.; Johnson, E. R.; Stradiotto, M. Adv. Synth. Catal., 2017, 359, 2972.

${ }^{160}$ Lin, X.; Phillips, D. L. J. Org. Chem., 2008, 73, 3680.

${ }^{161}$ Zhang, K.; Conda-Sheridan, M.; Cooke, S. R.; Louie, J. Organometallics, 2011, 30, 2546.

162 Tsou, T. T.; Kochi, J. K. J. Am. Chem. Soc., 1979, 101, 7547.

${ }^{163}$ Bakac, A.; Espenson, J. H. J. Am. Chem. Soc., 1986, 108, 719. 
${ }^{164}$ Zhang, C.-P.; Wang, H.; Klein, A.; Biewer, C.; Stirnat, K.; Yamaguchi, Y.; Xu, L.; Gomez-Benitez, V.; Vicic, D. A. J. Am. Chem. Soc., 2013, 135, 8141 .

${ }^{165}$ Zheng, B.; Tang, F.; Luo, J.; Schultz, J. W.; Rath, N. P.; Mirica, L. M. J. Am. Chem. Soc., 2014, $136,6499$.

${ }^{166}$ Lipschutz, M. I.; Tilley, T. D. Angew. Chem. Int. Ed., 2014, 53, 7290.

${ }^{167}$ Schley, N. D.; Fu, G. C. J. Am. Chem. Soc., 2014, 136, 16588.

${ }^{168}$ Han, F. S. Chem. Soc. Rev. 2013, 42, 5270.

${ }^{169}$ Quasdorf, K. W.; Antoft-Finch, A.; Liu, P.; Silberstein, A. L.; Komaromi, A.; Blackburn, T.; Ramgren, S. D.; Houk, K. N.; Snieckus, V.; Garg, N. K. J. Am. Chem. Soc., 2011, 133, 6352.

${ }^{170}$ Maeda, S.; Koichi, O.; Keiji, M. PCCP, 2013, 15, 3683.

${ }^{171}$ Bergeler, M.; Simm, G. N.; Proppe, J.; Reiher, M. J. Chem. Theory Comput., 2015, 11, 5712.

${ }^{172}$ Vaucher, A. C.; Reiher, M. J. Chem. Inf. Model., 2016, 56, 1470. 